\title{
LOS INICIOS DE LA COMPLEJIZACIÓN SOCIAL Y EL CAMPANIFORME EN EXTREMADURA ${ }^{1}$
}

\section{THE BEGINNINGS OF SOCIAL COMPLEXITY AND THE BELL-BEAKER IN EXTREMADURA}

\author{
por \\ VICTOR HURTADO PÉREZ
}

RESUMEN Se expone la información arqueológica sobre las últimas fases del Calcolítico extremeño y el proceso de complejización social que se empieza a producir antes de la llegada del campaniforme. En la comarca de Tierra de Barros es donde mejor se advierte la articulación de un territorio jerarquizado de base comunalista y defendido por poblados fortificados. El gran poblado de La Pijotilla sería el centro redistribuidor del territorio en el que se usa la religión como elemento de cohesión. La llegada del campaniforme no supondría cambios sustanciales, si no es para evidenciar las diferencias existentes ya en las relaciones interclánicas.

\begin{abstract}
The archaeological information about the last phases of the Chalcolitic in Extremadura and the process of social complex that is begun to produce before the arrival of Bell Beaker is exposed. In the region of Tierra de Barros is where better is warned the joint of a hierarchized territory of communal base and defended by fortified towns. The big settlement of La Pijotilla would be the distributor center of a territory in the one which is used the religion as cohesion element. The arrival of the Bell Beaker would not suppose substantial changes, if it is not to evidence the previous existing differences in the relationships amongst clan.
\end{abstract}

\section{Introducción}

La región de Extremadura presenta unas características fisiográficas muy diversas, por lo que no se pretende tratarla aquí como una unidad de análisis regional sobre la cual se pudiera considerar de manera uniforme la implantación de las comunidades prehistóricas a fines del III milenio a.n.e. Por otra parte la incidencia de las investigaciones realizadas en sus dos provincias, Cáceres al norte y Badajoz al sur, o Alta y Baja Extremadura, se ha desarrollado generalmente de forma diferente. En muchas ocasiones la bibliografía existente aporta una mayor información sobre la incorporación de nuevas localizaciones al

1. Este trabajo fue presentado en las Jornadas sobre "O Campaniforme" celebradas en Lisboa (Mayo de 1996) y organizadas por la Asociación de Arqueólogos Portugueses y que aún no ha sido publicado. 
inventario provincial de yacimientos que acerca del estudio sistemático de territorios concretos. Ello hace que a lo largo de este trabajo se haga referencia al estado de la investigación en cada una de las provincias de manera general. Sin embargo en la bibliografía arqueológica se suele emplear frecuentemente el término de Cuenca Media del Guadiana, en la provincia de Badajoz, como la principal área cuyas características geográficas permiten definir un espacio más acorde para el estudio de las sociedades prehistóricas. Por Cáceres otro río importante, el Tajo, atraviesa la provincia de este a oeste en una disposición paralela a la del Guadiana y en las últimas publicaciones se está utilizando el término de Cuenca Media del Tajo (i.e Galán y Martín 1991-92; Muñoz et alii 1995), aunque las características orográficas por donde discurre este río son muy diferentes al anterior. Ambos ríos son los principales ejes vertebradores de una extensa región dividida en el centro por los Montes de Toledo, limitada al norte y sur por cadenas montañosas, en medio de los cuales se encuentran paisajes de terrenos llanos y suaves lomas, como la típica dehesa extremeña, apta para el pastoreo, o más uniforme, como la amplia penillanura de Badajoz, junto al Guadiana, donde se concentran las mejores tierras para la agricultura (fig.1 y 3 ).

En la actualidad la base de información que se tiene de la prehistoria reciente de Extremadura es todavía desigual, sin embargo en los últimos años parece apreciarse una tendencia a equilibrar el nivel documental. La provincia de Badajoz y más concretamente el sector occidental de la Cuenca Media del Guadiana, es la que mejor se conoce en lo relativo a las culturas del III y II milenio a.n.e

Las recientes prospecciones efectuadas en la provincia de Cáceres han proporcionado un número de asentamientos calcolíticos similar al hasta ahora conocido en la provincia de Badajoz e investigaciones aplicadas sobre comarcas concretas muestran una alta densidad de ocupación. Es por ello que resulta necesario valorar con cautela posibles ámbitos de despoblamiento cuando en realidad pueden obedecer a vacíos de la investigación.

A principios de los años 80 y a raíz de las primeras excavaciones en los yacimientos de $\mathrm{El}$ Lobo y La Pijotilla se propuso una hipótesis de periodización para el Calcolítico de la Cuenca Media del Guadiana, que en gran parte coincidía con el esquema trifásico propuesto para el Calcolítico del Suroeste (Hurtado 1987; Enríquez-Hurtado 1986), aunque matizada por la secuencia estratigráfica local, con objeto de establecer unas mínimas bases de apoyo a los nuevos hallazgos de yacimientos calcolíticos.

En la segunda mitad de los años ochenta, al hilo de las nuevas tendencias investigadoras que se estaban aceptando en España, comienza a producirse alguna reacción en cuanto a las técnicas de estudio tradicionales, pero sin claras alternativas teóricas a cambio y sin que ello afectara a la periodización propuesta. El trabajo de J.J. Enríquez (Enríquez 1990) sobre los poblados calcolíticos de la Cuenca Media del Guadiana puede servir de referente para conocer el estado de la investigación a principios de los años noventa; éste se complementaría con una recopilación de sucintos informes sobre las últimas actividades arqueológicas publicadas en la serie Extremadura Arqueológica (vide Extremadura Arqueológica II y IV, 1991 y 1995). En ambas publicaciones nos basamos para realizar un trabajo de síntesis sobre la dinámica de poblamiento en la Cuenca Media del Guadiana y a él remitimos para una mayor aproximación a la secuencia cultural de la zona entre el IV y el II milenio a.n.e.(Hurtado 1995).

Del registro arqueológico existente se puede deducir que en Extremadura no se aprecian diferencias notables entre las fases del Calcolítico Pleno y la correspondiente al Campaniforme. Las aportaciones campaniformes se sobreponen al sustrato calcolítico sin alterarlo sustancialmente, hasta tal punto que podríamos considerar la última fase como un Calcolítico con campaniforme, como sucede en otras regiones. Sin embargo también es cierto que al final del III de milenio y coincidiendo con el nuevo repertorio artefactual se aprecian ya evidencias que nos indican que se han producido ciertas modificaciones. ¿Hasta qué punto se puede considerar que es durante la fase campaniforme cuando tienen lugar estos cambios, como si fuera la aparición del "campaniforme" el factor causal? 
La consideración trifásica tradicional supuso una segmentación en la evolución de este período que hacía obviar la búsqueda de explicaciones sobre los procesos internos de cambio, sobre todo en aquellas áreas de consideración marginal, como la extremeña, situada entre otros focos campaniformes de mayor entidad, como el de la Meseta, valle del Guadalquivir y la desembocadura del Tajo. Su situación intermedia parecía no necesitar de explicaciones a expensas de las que se pudieran dar en las áreas vecinas.

En la actualidad, y aunque el nivel de información aún no tenga la capacidad suficiente como para establecer consistentes inferencias explicativas, se ha producido, especialmente a escala regional y mediante prospecciones, un considerable aumento en el número de yacimientos calcolíticos, que posibilitan una mayor aproximación al conocimiento de este período.

\section{Registro poblacional}

Si a inicios de los años 80 el número de asentamientos calcolíticos conocidos en la provincia de Badajoz se limitaba prácticamente a dos, en el trabajo de J.J. Enríquez (1990), se puede observar que en 1990 esta cifra ascendía ya a 70, de los cuales 25 se encontraban junto al río Guadiana.

Entre el Guadiana y el Tajo existe una zona, la que se sitúa en torno al río Salor y Valencia de Alcántara, donde se localiza el mayor número de dólmenes de la región y que prácticamente se encuentra vacía de asentamientos al final del III milenio a.n.e, aunque ha sido objeto de reiteradas prospecciones (Fig. 2,A). Sería un ejemplo del cambio de estrategia poblacional que se produce a mediados del III milenio a.n.e. en busca de tierras fértiles.

Si tenemos en cuenta las áreas sobre las que ha incidido más la investigación (Fig 2) las mayores concentraciones de asentamientos se encuentran en las comarcas llanas y fértiles de Mérida y Tierra de Barros (Fig 2 E,D), especialmente en ésta última, donde estamos realizando un proyecto de prospecciones sistemáticas que elevan a 80 el número de asentamientos.

Por otra parte, al sureste, en la campiña de Llerena tenemos noticias de que se han localizado hasta un centenar de yacimientos (Fig 2, F), aunque en su mayor parte permanecen aún inéditos ${ }^{2}$.

En la provincia cacereña el conocimiento del número de poblados prehistóricos se ha visto incrementado notablemente por prospecciones, pasando de ser casi nulo en la década anterior hasta llegar a contabilizarse en la actualidad 69 asentamientos calcolíticos (González 1993). El grueso de la información procede de las investigaciones realizadas por A. González Cordero, quien a través de sus estudios principalmente en el área de Plasenzuela (Fig 2, B), proporcionó las bases para el establecimiento de la secuencia cultural de la zona.

La información actual procedente de excavaciones es sin embargo relativamente escasa, no llegando a suponer más del $21 \%$ del total ( 15 yacimientos), proporción que se reduce a la mitad si contabilizamos los poblados excavados en extensión. Los desajustes se acentúan observando las zonas donde se han realizados mayor número de excavaciones, como las del valle occidental del Guadiana, entre Mérida y Badajoz, que suponen el $27 \%$ frente a la práctica inexistencia en el valle oriental.

En Cáceres, los poblados excavados se encuentran al sur del Tajo y suponen un $20 \%$, frente a los prospectados, una proporción similar a la existente en la provincia de Badajoz.

Esta información, aunque resulta válida para el establecimiento de una secuencia cultural en el conjunto extremeño, no lo es tanto para una investigación más detenida sobre otros aspectos como el socioeconómico, demográfico, o de implantación territorial entre otros.

2. Información oral proporcionada por J. Iñesta. 


\subsection{EI territorio}

A lo largo de la segunda mitad del III milenio se incrementa el número de asentamientos por toda Extremadura. Ya no son sobre todo las zonas llanas próximas al gran río Guadiana las que se encuentran ocupadas, sino que se colonizan nuevos territorios cuyas tierras presentan diferentes capacidades para su explotación agrícola. Es evidente que aquellas tierras más fértiles serán más densamente pobladas, junto a pequeños ríos y arroyos. Es un fenómeno de expansión que se produce igualmente en diversas regiones relacionado con un incremento demográfico y posiblemente motivado por un incremento en la productividad agrícola (García y Hurtado 1997, 141). En Extremadura las diferencias en la ocupación del espacio entre la primera y segunda mitad del III milenio a.n.e. se hacen más evidentes cuando se compara la distribución de estructuras megalíticas y hábitats dispersos por las estribaciones montañosas al norte y sur del Guadiana y la posterior ubicación de numerosos poblados de carácter estable en la penillanura.

En la segunda mitad del milenio se observa una fuerte diversificación de los asentamientos que, en atención al orden de mayor a menor número de localizaciones, se pueden considerar en pequeños poblados situados en llano o en cerros estratégicos, poblados fortificados de pequeño tamaño y grandes poblados.

Los poblados comenzarían a fortificarse en Extremadura a partir del 2.200 a.n.e, según indican las dataciones absolutas de varios asentamientos excavados. En el área de Plasenzuela, al norte del Guadiana (Fig 2, B), y prospectada intensamente se encuentran concentrados una serie de poblados fortificados y sin fortificar. Dos de estos, sin campaniforme, Cerro de la Horca Ila y Cabrerizas se fechan respectivamente en el $4.215 \pm 100$ BP y $4060 \pm 85$ BP (González et alii 1991).

Otros dos poblados fortificados, además de un fortín (con un repertorio de materiales similar al Cerro de la Horca IIa) ubicado en un cerro estratégico con funciones de vigilancia y cercano a un poblado de llanura, corresponderían, según sus excavadores, a un momento algo más avanzado por el conjunto de materiales, aunque por la ausencia de campaniforme ${ }^{3}$ consideran anterior a esta fase (González et alii 1991: 25).

En la Cuenca Media del Guadiana (Fig 2,E) el asentamiento de Palacio Quemado (Alange, Badajoz) ha proporcionado las fechas de $4140 \pm 80 \mathrm{BP}$ y $3570 \pm 100 \mathrm{BP}$ para dos momentos de ocupación (Hurtado y Enríquez 1991), siendo la primera fase, pues, coetánea de Cabrerizas. Aquí parece existir un primer momento ${ }^{4}$ durante el cual varias cabañas se encuentran desprovistas de defensa. Con posterioridad se construye una plataforma de piedra y tierra flanqueada por un muro y bastión durante el cual tuvo lugar un gran incendio que arrasó el poblado. En una siguiente fase todo el hábitat se cerró mediante un muro de un metro de anchura (Hurtado y Enríquez 1991).

La Palacina es otro poblado fortificado que se encuentra próximo al anterior, situado sobre una pequeña loma y en la desembocadura del mismo río. Tiene una hectárea de extensión y se advierten en superficie tres líneas defensivas, en lugar de una o dos que suelen ser habitual en este territorio. El muro interior, el mejor conservado y de un metro de anchura, se construye con "piedras de gran tamaño y un relleno interno de tierras y piedras pequeñas (Enríquez 1990: 52), similar al de la segunda fase de Palacio Quemado.

La escasa información de este asentamiento procede de un sondeo en el que apareció un solo nivel de ocupación con presencia, entre otros ítemes, de cerámica campaniforme y objetos de metal, lo que supone la única evidencia hasta ahora de un poblado erigido en este momento, quizás para el control del paso natural. En la fase siguiente, Solana-Guadajira (Hurtado 1995), se abandona el sitio para ocupar el cercano cerro

3. La ausencia de cerámica campaniforme no puede ser considerada como determinante para la adscripción cronológica de un yacimiento en esta región ya que existen ejemplos de yacimientos que sabemos pueden corresponder a este momento y no hallar restos de cerámica de este tipo. Por otra parte hay que tener en cuenta la escasez de cerámica campaniforme en Extremadura.

4. La excavación en el sector de la primera muralla no llegó hasta la base, por lo que no se pudo precisar la conexión estratigráfica con las estructuras de la primera fase. 
del Castillo de Alange, la mayor elevación de la zona y en la que se encuentran las mejores evidencias de la Edad del Bronce en la región (Pavón 1994 y 1998).

El caso de la comarca de Tierra de Barros (Fig. 2, D y 3) es particularmente interesante por cuanto aporta la mejor información para comprender la distribución de los asentamientos calcolíticos en un territorio concreto.

La Pijotilla es el asentamiento de mayor extensión de la región y uno de los mayores poblados del Suroeste peninsular, junto a los de Valencina de la Concepción en el valle del Guadalquivir (Martín y Miranda 1988) y Ferreira do Alentejo en Portugal (Arnaud 1982).

Observando el mapa de distribución de los hábitats calcolíticos (Fig. 3) el territorio de Tierra de Barros quedaría enmarcado al norte y oeste por la curva del río Guadiana y al sur por las estribaciones montañosas de Sierra Morena, mientras que la zona oriental, de más fácil acceso, se cierra con una línea de poblados fortificados. Se trata, pues, de un espacio definido geográficamente por un tipo de terreno llano y arcilloso, limitado por una cadena de elevaciones y un río, a los que se añade una disposición de fortificaciones en hilera para completar su cierre (Hurtado 1995).

Al sureste de la provincia de Badajoz, en la campiña de Llerena (Fig. 2, F), los asentamientos con campaniforme, a excepción de Huerta de Dios, se conocen mediante prospecciones superficiales. Se trata de un territorio situado al límite de las estribaciones de Sierra Morena donde se encuentra una diversidad de asentamientos similar a la de Tierra de Barros, instalados en un terreno de abundantes recursos agrícolas y mineros, además de ser una vía de comunicación entre la Cuenca media del Guadiana y el Valle del Guadalquivir. A pesar de las escasas investigaciones se adivina en este territorio una estructura espacial jerarquizada que convendrá estudiar atentamente. Al único poblado parcialmente excavado, Huerta de Dios (Enríquez 1983), situado en llano y sin fortificaciones, se le calcula un tamaño de 10 has, lo que haría considerarlo el mayor de toda la zona, sin embargo la amplia distribución de artefactos calcolíticos por diversos puntos de la localidad de Llerena podría hacer que aquí se situara otro gran asentamiento de extensión ${ }^{5}$. Otros dos poblados con campaniforme se encuentran fortificados, su tamaño es muy reducido y se encuentran junto a minas de cobre (Enríquez 1990; Enríquez e Iñesta 1985).

En otras zonas, como el suroeste extremeño, no se han realizado suficientes investigaciones sobre el territorio y sólo se conocen de forma aislada algunos poblados situados en altura y fortificados; el de Trasera de La Pepina, en Fregenal de la Sierra (Fig. 2, G), controla un importante paso natural y de aquí procede un fragmento de campaniforme inciso entre los materiales de superficie (Enríquez 1990: 89).

Del análisis territorial y sobre la base de la información de la que se dispone se pueden extraer sugerentes interpretaciones:

Si se asume la coetaneidad de los asentamientos distribuidos en Tierra de Barros y en atención a las diferencias de tamaño, existe una marcada jerarquización entre ellos, aunque quedarían por establecer sus niveles de funcionalidad. La mayor parte de los asentamientos situados en el interior de Tierra de Barros se compone de poblados de 1 a 3 has. de extensión que ocupan terrenos llanos junto a pequeños ríos y carecen de defensas. Los poblados fortificados se sitúan en la margen oriental de esta comarca a lo largo de una línea norte-sur de la que se podría inferir la formación de un límite defensivo que cubriría el sector menos protegido topográficamente de un territorio con características homogéneas (Fig. 3). Constituiría un espacio transicional de delimitación de un territorio social y/o económica y/o políticamente articulado, de unos 60 por $30 \mathrm{kms}$ vertebrado por un asentamiento central (Hurtado 1995; García y Hurtado 1997: 141)

5. Información oral de J. Iñesta. 
Es desde esta perspectiva macroespacial donde mejor se explicaría la situación del poblado de La Pijotilla: éste sería el principal centro de un territorio en que la riqueza agrícola del suelo se erigiría como la causa fundamental de su control. La elección del territorio de Tierra de Barros se debería, fundamentalmente, a su homogeneidad y óptimas condiciones agrícolas, en especial para el cultivo de cereales y leguminosas.

En esta hipótesis los yacimientos fortificados de este espacio no erigirían las murallas para defensa de su población, como se interpreta en otros casos, sino para protección del territorio

La exposición de esta hipótesis no hace más que definir una unidad de análisis territorial a partir de la cual será necesario conocer la formación económico-social que la estructura, la articulación de su dinámica interna, o las interacciones centro-periferia, que nos permitirían fijar adecuadamente el modo de organización del territorio (Castro-González 1989; Nocete 1984).

La hipótesis no deja de plantear múltiples cuestiones acerca de la complejidad social y la mecánica de la estructura de poder que se empieza a desarrollar a fines del III milenio a.n.e. y en las que resulta necesario profundizar. Existen todavía pocas bases para su definición; pero también algunas pautas permiten ir clarificando los presupuestos en los que se desenvuelve la dinámica interna de la sociedad, como veremos en los contextos funerarios.

\subsection{Los poblados}

Si atendemos solamente a los poblados con campaniforme nos encontramos con una relativa escasez de información, sobre todo en lo referente a estructuras de habitación, ya que son muy pocas las excavaciones en extensión.

Los poblados excavados muestran la continuidad del hábitat con la superposición estratigráfica de elementos campaniformes. Así en el área de Plasenzuela el único sitio con campaniforme es el de Cerro de la Horca donde en su nivel II b se encuentran cerámicas campaniformes de diversos tipos junto a objetos metálicos de cobre y evidencias del proceso de producción (González et alii 1991: 16), mientras que las estructuras de habitación son prácticamente iguales a las de la fase anterior. Los demás poblados de esta área no tienen cerámica campaniforme, lo cual es interpretado como un despoblamiento de la zona debido a "una nueva orientación económica, como es la explotación de los distintos filones metalíferos que afloran en el subsuelo de la comarca" (González et alii 1991: 25). A este respecto resulta significativo el aumento de producción metalúrgica en el nivel campaniforme del Cerro de la Horca frente a los restantes poblados de la fase anterior.

La misma continuidad estratigráfica y mayor presencia de metal se observan en el poblado fortificado de Los Barruecos, Malpartida de Cáceres (Sauceda 1991), mientras que en Los Castillejos de Santiago del Campo la confusa excavación no permite diferenciar los distintos niveles estratigráficos, en los que se mezclan materiales campaniformes y de la Edad del Hierro (Esteban y Salas 1991).

Otra zona más intensamente explorada al nordeste de la provincia, concretamente al sur de Navalmoral de la Mata y en el sector de Valdecañas (Fig. 2, C), se han dado a conocer recientemente por prospección nueve asentamientos calcolíticos, de los cuales en sólo uno, el Recorvo, aparece cerámica campaniforme. A diferencia del área de Plasenzuela el estudio de materiales de esta zona lleva a A. González Cordero a considerarla relacionada más con la Meseta que con la Cuenca Media del Guadiana (González 1998: 480).

Los restantes poblados cacereños son conocidos únicamente mediante prospecciones, aunque sorprende el hecho de que en los alrededores del río Tajo no aparezca material campaniforme (González 1993).

En la provincia de Badajoz los hábitats con campaniforme de la comarca de Mérida se sitúan a la orilla izquierda del río Guadiana. Alangón es un asentamiento ubicado sobre un cerro estratégico que controla 
el vado del río; la única evidencia de campaniforme es la de una punta Palmela hallada en superficie, mientras que en el pequeño sondeo apareció parte de una cabaña con zócalo de piedras (Enríquez 1990: 133). Otros poblados, hallados en prospecciones, se asientan en llano o sobre suaves lomas y tienen un tamaño que no alcanza 1 ha. de extensión (Enríquez 1990).

En Palacio Quemado las estructuras de habitación varían de una fase a otra. De la planta elipsoidal de la primera fase se cambia en la segunda a otra de forma circular de $6 \mathrm{mts}$. de diámetro y construida con un muro de adobe reforzado con zócalo de piedras (Hurtado y Enríquez 1991). En este poblado no se conocen estructuras de almacenamiento como silos u otro tipo de contenedores, aunque es posible que en la cabaña circular, solamente descubierta hasta ahora en el nivel superficial, pueda hallarse algún gran recipiente, como el de Cabrerizas, en Plasenzuela (González et alii 1991: 21).

La más precisa información de esta región procede de las excavaciones del asentamiento de La Pijotilla, Badajoz (Hurtado 1984 y 1991). Aquí, el tamaño del yacimiento ha podido ser delimitado con mayor exactitud por fotografía aérea. Desde el aire se puede apreciar el contorno circular de casi un kilómetro de diámetro que forma un foso rodeando una extensión de 1000 x $800 \mathrm{mts}$. (Hurtado 1991). En el interior de este gran círculo exterior se observa en las fotografías un arco de otro círculo más reducido, que aún no ha sido suficientemente explorado y en el que parecen concentrarse estructuras de habitación. En el sector oriental, y dentro del círculo exterior, se sitúan varias tumbas que indican la utilización de este espacio como necrópolis (Fig. 4).

$\mathrm{El}$ foso exterior conserva un acceso murario con dos paredes de piedra dispuestas en paralelo y una construcción aislada de piedras en forma de media luna (de difícil interpretación). La consideración del foso como recinto defensivo carece de lógica por las escasas condiciones de estrategia, puesto que la topografía del lugar, una suave cuenca en cuyo fondo se sitúa el poblado, haría poco efectiva la defensa del poblado. Más bien este gran foso tendría, entre otras, la función de desviar las aguas de lluvia torrencial que bajaban por la ladera, protegiendo el poblado de inundaciones. En el caso del reciente hallazgo del gran poblado de Marroquíes Bajos en Jaén se ha descubierto un complejo sistema de cierre del área habitacional compuesto por varios anillos concéntricos de fosos y murallas (Hornos, Zafra y Castro 1998). Los autores de la investigación parten de la hipótesis de que se trate de un "circuito hidrológico... que captaría el agua... de los cerros y la distribuiría por toda la extensión de construcciones y campos del asentamiento" (Hornos, Zafra y Castro 1998: 85), lo cual no sería posible en La Pijotilla debido al desnivel en el que se encuentra excavado el foso exterior. El foso permitiría, pues, conducir las aguas de lluvia hacia el punto más bajo, el arroyo que cruza el poblado por la mitad.

El mencionado semicírculo interior, situado en el sector occidental del asentamiento, se interrumpe en el mismo arroyo. Este segundo foso ${ }^{6}$ delimita una zona del poblado más reducida y, según la prospección intensiva de superficie realizada sobre el asentamiento, es aquí donde se concentra la mayor cantidad de cerámica campaniforme del sitio (Hurtado 1999). Ello parece indicar que durante esta fase el tamaño del poblado se reduce considerablemente, volviéndose a construir un sistema de cierre en zanja similar al anterior.

En cuanto a la organización interna del hábitat se dispone de datos procedentes de excavaciones en extensión realizadas en varios sectores del asentamiento, principalmente en los sectores oriental y central. En ninguna de las estructuras de habitación halladas hasta ahora aparece campaniforme, por lo que resulta difícil determinar si algunas de ellas pertenecen a esta fase. Por otra parte conviene señalar que los niveles superiores del yacimiento fueron arrasados tras las primeras actividades agrícolas de los años $70 \mathrm{y}$ en esos momentos aún se podían observar círculos de piedra en superficie que pudieran corresponder a las

6. En este sector no se ha realizado aún excavaciones. El semicírculo se advierte a través de fotografías aéreas y la consideración de foso se pudo determinar tras el corte efectuado por la zanja del gasoducto. 
cabañas de las últimas fases. Ya se ha comentado que en Palacio Quemado la cabaña de la segunda fase se construye con zócalo de piedras (Hurtado y Enríquez 1991) y en el asentamiento con campaniforme de Molino Perdido ${ }^{7}$, Aceuchal, se observan en superficie construcciones circulares de piedras. También en Huerta de Dios, en la campiña de Llerena (Enríquez 1983 y 1990), se localizó una estructura cuyo sistema de construcción hizo pensar en un primer momento a los excavadores que se tratara de una tumba tipo tholos "tanto por sus dimensiones y monumentalidad, como por lo excepcional de los materiales arqueológicos exhumados" (Enríquez 1990: 82). Dicha estructura es de planta circular y se construye mediante un "alzado de hileras de piedras que cerraban en falsa cúpula" (Enríquez 1990: 82). De la información disponible tampoco se puede precisar si se trata de una estructura de habitación, sobre todo teniendo en cuenta que el conjunto de ítemes hallado en su interior no suele aparecer en este contexto, tales como ídolos sobre huesos largos, ídolos placas y betilos, además de un peine y una espátula de marfil. Por otra parte se hace hincapié en el abundante número de artefactos líticos tallados y pulimentados, así como en la variedad cerámica, entre la que se incluye un fragmento de campaniforme "decorado con puntillado e incisiones" (Enríquez 1990: 188). Las únicas evidencias de estructuras constructivas similares a la de Huerta de Dios se encuentran, como veremos, en las tumbas de Guadajira, lo que puede ser indicativo de un sistema de construcción más generalizado en la región que se aplica tanto en estructuras domésticas como funerarias durante el final del período calcolítico.

En el centro del asentamiento de La Pijotilla se localizaron zanjas correspondientes a los primeros momentos de la vida de este poblado y similares a las que aparecen en poblados como Valencina de la Concepción en Sevilla y Papa Uvas en Huelva. Con posterioridad estas zanjas se colmataron como basureros y sobre ellas se halló una cabaña sin campaniforme, pero ya con una cronología de principios del II milenio $(3860 \pm 70 \mathrm{BP}=1910$ ane-2.350 ANE). En las últimas intervenciones y debido a la accidental apertura de una zanja para gasoducto se localizaron concentradas en el sector central varias cabañas y silos de mediano tamaño, bastante próximas entre sí. En una de ellas se obtuvo la datación de $4010 \pm 80$ BP y entre los artefactos se encontraban tipos de cerámicas de paredes finas (frecuentemente asociadas en el territorio a los momentos finales del Calcolítico y a la fase de tránsito al Bronce), un cuchillo de cobre y un ídolo oculado en hueso.

En La Pijotilla existe variedad de silos en relación con el tamaño, todos ellos excavados en la tierra, tanto en terrenos calizos como arcillosos. Los más grandes se encuentran aislados en los extremos del yacimiento, los más pequeños, en el interior de las cabañas. Uno de ellos, situado en el sector occidental y denominado $\mathrm{E} 4$ mide 3,5 mts de diámetro, con una profundidad similar. En el nivel base y una vez que se abandona como lugar de almacén, se obtuvo la fecha más antigua del yacimiento: $4360 \pm 50 \mathrm{BP}$. Otra datación corresponde al nivel medio, cuando se aprovecha la estructura como lugar de habitación: $4100 \pm$ $40 \mathrm{BP}^{8}$. Posterior a esta fecha aparece un fragmento de campaniforme inciso en un nivel de relleno del silo. Otros silos de mediano tamaño, e igualmente alejados de las cabañas, se sitúan en el sector oriental, algunos de ellos reutilizados posteriormente como lugares de enterramiento.

La variable relativa a las unidades de almacenamiento de los productos subsistenciales puede ser utilizada para delimitar formaciones sociales jerarquizadas y estratificadas (Haas 1982, García 1996). En nuestro caso las dataciones absolutas y la estratigrafía del silo E4 indican que los silos de gran tamaño corresponden a la fase más antigua del asentamiento, posiblemente en relación con el carácter colectivo de las estructuras de almacenamiento y el acceso igualitario de la población a los recursos alimentarios.

Sin embargo, en la fase campaniforme no tenemos evidencias claras de cómo se manifiestan las relaciones de producción a través de esta variable. El abandono de estos grandes silos y las unidades de almacenamiento individuales situadas junto a las cabañas podrían ser indicativos de un acceso diferencial a

7. Asentamiento aún inédito, localizado en las recientes prospecciones del río Guadajira.

8. Dataciones recientemente realizadas en los laboratorios Beta Analytic Inc.: (Beta-121146)4110 -40 BP/2160 ane/1 sigma cal: 2860-2585 ANE; (Beta-121147) 4360 50 BP/2410 ane/l sigma cal: 3030-2905 ANE 
los recursos en un momento posterior. En el caso del sureste peninsular Chapman observa el contraste entre el almacenamiento probablemente colectivo de los silos calcolíticos situados al exterior de las viviendas y el particular de los recipientes argáricos ubicados en el interior (Chapman 1991: 218), pero es probable también que junto a los silos de almacén domésticos coexistan otras grandes estructuras para albergar el excedente alimentario que las élites utilizan en su papel redistribuidor.

\section{Registro funerario}

Las investigaciones mediante prospecciones que se han realizado en Extremadura proporcionan información básicamente sobre poblados y muy poca acerca de los enterramientos. Es por ello que las tumbas excavadas son escasísimas y aún más las correspondientes al final del Calcolítico. De hecho la mayoría de las escasas evidencias campaniformes halladas en contextos funerarios proceden de la reutilización de tumbas megalíticas.

En El Guadalperal, Cáceres (Leisner y Leisner 1960), es frecuente la abundancia de microlitos, puntas de flecha y láminas de sílex, junto a un número considerable de hachas pulimentadas, pero aquí son más numerosos los vasos campaniformes tipo Ciempozuelos (Fig. 7, A) y cerámicas decoradas con la técnica de "pastillas repujadas" (González 1993: 251). Las relaciones con la Meseta en esta zona cacereña son evidentes por la similitud de la cerámica campaniforme; la cerámica de "pastillas repujadas", sin embargo, aunque participa de una técnica decorativa más extendida por el occidente peninsular, presenta unas particularidades propias de la zona al norte del Guadiana y de ello se tratará más adelante.

Y a excepción del tholos de El Guadalperal, el único conjunto de enterramientos con campaniforme se localiza en la Cuenca Media del Guadiana. Aquí, el Dolmen de Lácara es el mayor sepulcro de corredor de la región y su interior se encontraba totalmente removido, siendo difícil diferenciar las inhumaciones correspondientes a una $u$ otra época (Almagro 1959). El ajuar es similar a El Guadalperal en cuanto a la industria lítica y, junto a varias alabardas, se contabilizan más de cien puntas de flecha, microlitos y cuchillos de sílex, además de algunos recipientes cerámicos, un ídolo placa, cuentas de collar y colgantes, dos puntas de cobre tipo Palmela (Fig. 7, D) y un fragmento campaniforme inciso decorado (Fig. 8, 5). en el interior y exterior. Las puntas Palmela aparecen también en el tholos de Colada de Monte Nuevo, Olivenza (Fig. 10, E), esta vez sin cerámica campaniforme, aunque acompañadas de vasos de "paredes finas" y junto a enterramientos secundarios, que llevaron a Schubart a la consideración de que se trataba de posteriores inhumaciones de la Edad del Bronce (Schubart 1973).

En la misma zona que la tumba anterior Mélida dio a conocer un hallazgo casual en un lugar conocido como Dehesa de La Pestaña (Mélida 1925: 56), también llamado por Molina Los Fresnos (Molina 1979) cuya descripción permitió a éste último considerar que se trataba de una tumba atendiendo a las características de montículo artificial aislado y restos de huesos humanos. Entre el conjunto de piezas rescatadas se encontraba un puñal campaniforme (Fig. 10, A), además de otras piezas metálicas, entre las que se menciona una "punta de flecha de larga espiga", hoy desaparecida, ídolos oculados en mármol y betilos. L. Molina considera que podría tratarse de una tumba tipo tholos, por el tipo de ajuar y piedras de tamaño mediano, no ortostatos, pero también pudiera corresponder a una estructura circular sin corredor, como las que aparecen en La Pijotilla o Guadajira.

En la Pijotilla los sepulcros se encuentran en el sector oriental y dentro del recinto circular formado por el foso exterior. A la fase precampaniforme corresponden dos tumbas de tipo tholos, las cuales presentan una disposición en $\mathrm{V}$ y, por tanto, con diferentes orientaciones (Fig. 5). El sistema de construcción es muy similar en ambos casos, en su mayor parte se encuentran excavadas en la tierra caliza, por lo que 
solamente se utilizaron piedras calizas extraídas del mismo sitio para la construcción de la falsa cúpula y otras, las menos, de granito y pizarra para la puerta de entrada (Hurtado 1986 y 1995)

Las cubiertas de las dos tumbas se desplomaron debido a la poca consistencia de los materiales y este hecho permitió localizar el contenido intacto. Los enterramientos que se realizaron tras el derrumbe, tanto los practicados en el corredor como encima del desplome de la cámara, parecen corresponder a la misma fase; ello supone que ambas estructuras tuvieron una corta duración, al menos ésta no alcanzaría la fase campaniforme.

La única cronología radiocarbónica obtenida ${ }^{9}$ procede del nivel medio de la tumba $\mathrm{T} 3$ y ha proporcionado la fecha de $4130 \pm 40 \mathrm{BP}$, lo cual podría indicar que en el último siglo del III milenio (en fechas no calibradas) se habría dejado de utilizar.

La cuestión que se plantea es si las dos sepulturas son coetáneas o no. Precisamente el hecho de que se encuentren unidas, por su disposición en $\mathrm{V}$, nos hace pensar que la tumba $\mathrm{T} 3$ podría ser más antigua. El inicio del corredor en ambas estructuras está formado por una pequeña zanja y en el caso de T3 ésta es cortada por la zanja de T1 que, además, se encuentra excavada a mayor profundidad. Por otra parte los ajuares de una y otra tumba son diferentes, más simples en el caso de T1 y más variada y rica en T3; así, mientras en T1 (con 80 enterramientos) cada individuo posee una lámina de sílex y, en ocasiones, una punta de flecha y un trozo de ocre, en T3 (que contenía 300 enterramientos) predomina como ajuar un recipiente cerámico de pequeño tamaño. En el interior de T1 se encontró, además, un vaso de mármol, buriles de cristal de roca, un peine de hueso, varias falanges pintadas de ocre y unas cuentas de collar (Hurtado 1986). En T3 se observan, sin embargo, más diferencias en el ajuar: cuentas de collar, vasos de hueso, conchas marinas, ídolos falange, ídolos sobre huesos largos, figurillas antropomorfas, o betilos, entre otros artefactos; en algunos casos, como los grandes vasos situados junto a la entrada, podrían formar parte del ajuar colectivo. Una de las inhumaciones de T3 destacaba por el tipo de ajuar que le acompañaba, consistente en un puñal de cobre con dos escotaduras, dos vasos cerámicos, una lámina de sílex y restos de ocre y limonita, pero en el modo de enterramiento, colocado junto a otras inhumaciones y en la misma disposición encogida, no parecía sobresalir de los demás.

La mayor cantidad y variedad de artefactos sociotécnicos e ideotécnicos en T3 frente a la homogeneidad del ajuar de T1 nos puede llevar a suponer un desarrollo en los modos de enterramiento marcados por la diferenciación del grupo social, por lo que a este respecto T3 podría ser considerada posterior a T1. A ello contribuiría, además, la presencia del puñal de cobre, cuyo carácter sociotécnico en el contexto de la tumba se constituye en un indicador del estatus relevante que el individuo comienza a adquirir dentro de la comunidad y un exponente de la tendencia cada vez más acusada hacia la personalización e individualización en el ritual funerario.

Sin embargo existen otras consideraciones que surgen de la comparación entre una y otra tumba. Asumiendo que ambos enterramientos colectivos hubieran sido utilizados de forma sincrónica o casi sincrónica las diferencias en la naturaleza de los ajuares obedecerían a la distinta capacidad de prestigio que puedan alcanzar las diversas unidades parentales (García y Hurtado 1997: 145).

Si por el contrario se considera desde una perspectiva diacrónica se constata una tendencia hacia la progresiva disminución del número de inhumaciones en el interior de las tumbas: 300 individuos en T3, 80 en T1, 34 en T2 (Campaniforme), entre 5 y 11 individuos en las tumbas de Guadajira, hasta los enterramientos individuales de la Edad del Bronce. A este respecto la tumba T1 podría considerarse posterior a T3 y estaría en consonancia con la evidencia estratigráfica antes mencionada.

9. La datación corresponde a una muestra de carbón (Beta-121143) 4130 \pm 40 BP/2180 ane/1 sigma cal: 2865-2595. Varias muestras de huesos de diferentes niveles escogidas en las dos tumbas y enviadas junto a la de carbón al laboratorio Beta Analysis han dado resultados negativos. 
El interés del análisis comparativo entre las tumbas T1 y T3 no tendría mayor significación si lo tratamos en términos de evolución social y en una escala temporal amplia. Sin embargo entender el hecho de que cada una manifieste diferencias en los ajuares y ambas correspondan a una misma fase posibilitaría comprender mejor, a través del registro funerario, el proceso de cambio del sistema de relaciones sociales de producción, basado en el parentesco, hacia una estructura progresivamente jerarquizada.

Justo en la periferia del territorio de Tierra de Barros, en Almendralejo, se encuentra el tholos de Huerta Montero construido, como en la Pijotilla, mediante excavación en la tierra arcillosa, aunque para el corredor y la cubierta en falsa cúpula se utilizaran piedras de gneiss y pizarra ((Blasco-Ortiz 1991). En su interior se detectaron dos fases de ocupación, con un mayor número de inhumaciones en la primera y otro menor en la segunda. El ajuar entre una y otra no presenta diferencias notables ${ }^{10}$, a pesar de que las cronologías absolutas indican un dilatado período de ocupación de casi mil años. La datación de la primera fase corresponde a $4650 \pm 250 \mathrm{BP}$, es decir 2700 a.n.e, una fecha que resulta muy alta teniendo en cuenta, además, su elevada desviación típica. Para la segunda fase se obtuvieron dos fechas, una al inicio de la ocupación de $4220 \pm 100$ BP (2270 a.n.e.), coincidiendo aproximadamente con la fecha de T3 y $3720 \pm 100$ BP (1770 a.n.e.), para los últimos enterramientos. Ello supondría que cada fase tendría una duración de 500 años, manteniéndose el mismo ritual colectivo y tipos de ajuar, incluso durante las fases campaniformes y de tránsito al Bronce, lo que implica una pervivencia en las prácticas funerarias que no parece concordar con lo que sucede en el mismo territorio.

Hacia el final del III milenio a.n.e. la construcción de sepulcros con grandes ortostatos decrece, pues, ostensiblemente, suponiendo con ello un descenso en la inversión de trabajo y un menor esfuerzo de coordinación colectiva (García 1996).

Los grupos clánicos sólo precisan de un escaso número de operarios para construir las tumbas mediante la excavación en tierra de la mayor parte de las estructuras funerarias, en especial cuando la piedra no sea abundante en la zona. El esfuerzo físico es sustituido por la habilidad técnica al aplicarse en el alzado de la estructura en falsa cúpula.

Pero esta tendencia a reducir el esfuerzo constructivo continúa manifestándose durante las fases siguientes, y se observa en el menor tamaño de los sepulcros o incluso, como en Colada de Monte Nuevo y Lácara en la reutilización de otros anteriores.

En La Pijotilla y junto a las tumbas T1 y T3 se halló una tercera, T2, de forma circular que contenía cerámica campaniforme en su interior (Hurtado 1986). Dicha tumba medía 3,5 mts de diámetro y era de construcción muy simple, consistente en un círculo de pequeñas pizarras colocadas en vertical y parcialmente hincadas en una pequeña zanja rellena de tierra para su mejor sujeción (Fig. 6) Aunque la tumba sufrió los efectos del arado y la consiguiente remoción del terreno, la mayor parte de las losas de pizarra se mantuvieron en su lugar original, comprobándose que su función era la de limitar el exterior de la sepultura. Por el contrario no se conservaba ningún indicio de la cubierta.

Evidentemente el arado había afectado a la colocación original de los enterramientos y al ajuar y aunque la reja subsoladora volteó el contenido de la tumba, sin apenas arrastrarlo, los restos óseos se fragmentaron considerablemente. A pesar de ello el estudio antropológico ${ }^{11}$ pudo determinar que el número de individuos enterrados era de 34 ( 16 adultos, 5 jóvenes y 13 niños) pero resultó imposible asociar a cada uno de ellos el ajuar correspondiente (Hurtado 1984).

La cerámica no era abundante y a excepción de un pequeño vaso esférico y un cuenco semiesférico completos, se pudieron reconstruir parcialmente otros cinco recipientes entre los 30 fragmentos localizados,

10. La información existente se limita a un reducido informe, sin que hasta el momento conozcamos con exactitud el número de inhumaciones por fase (en total se estima en un centenar), artefactos hallados, etc.

11. El análisis antropológico fue realizado por el Dr. García Sánchez de la Universidad de Granada y será publicado próximamente en su totalidad junto al estudio de las demás tumbas. 
casi todos de reducido tamaño. El resto del ajuar se componía de ídolos falanges decorados, ídolos placa, un ídolo tolva, un vaso de mármol, varias cuentas de collar, además de láminas de sílex y puntas de flecha. A ellos hay que sumar un vaso campaniforme completo y el fragmento de otro, ambos decorados con puntillado geométrico (Fig. 6).

La proximidad en la que se sitúan las tumbas T1 y T2 sugiere que la segunda debió construirse en un momento posterior a la primera. La tumba circular $\mathrm{T} 2$, a sólo $3 \mathrm{mts}$ de distancia de la cámara de $\mathrm{T} 1$, indicaría que la estructura circular se construiría una vez que la cubierta de T1 se hubiera desplomado y el túmulo hubiera desaparecido, ya que éste, de existir, llegaría a invadir su espacio.

Se tienen noticias del hallazgo reciente de otra tumba campaniforme en Barbaño, situada en llano junto a la orilla derecha del Guadiana y a corta distancia de Guadajira y La Pijotilla. En ella aparecieron varios vasos campaniformes y un conjunto de piezas de oro que desaparecieron por la acción de los expoliadores ${ }^{12}$. Según algunos testigos la tumba era de planta circular, construida con barro o adobes y con cubierta en falsa cúpula.

Otras tumbas de estructura circular y con material campaniforme en su interior se localizaron en Guadajira, a unos 5 kms de La Pijotilla (Hurtado 1995; Hurtado y García 1996).

A diferencia de la tumba circular de la Pijotilla las sepulturas de Guadajira se sitúan en la ladera de un cerro y no en llano. Hasta ahora se han descubierto tres tumbas ${ }^{13}$. Las tres tienen planta circular y con un diámetro que oscila entre los 2,70 mts y los 3,5 mts; dos de ellas (tumbas 1 y 3 ) se construyeron aprovechando la inclinación de la ladera y excavándose parcialmente en la roca y una tercera (tumba 2), se erigió con hiladas de piedra formando una falsa cúpula desde el suelo.

Aunque todas habían sido saqueadas se localizaron los restos de los enterramientos removidos, pudiéndose determinar, a través del estudio antropológico, la existencia de cinco inhumaciones en la tumba 1 , once (seis niños y cinco adultos) en la tumba 2 y dos (un niño y un adulto) en la tumba 3.

El ajuar de la tumba 2 había desaparecido en su totalidad ${ }^{14}$ y posiblemente parte del correspondiente a las restantes tumbas. Aún así el número de artefactos cerámicos resultó ser bastante numeroso, contabilizándose hasta 56 los recipientes completos o casi completos hallados entre las tumbas 1 y 2.

Este ajuar se componía básicamente de pequeños vasos (predominan los intervalos comprendidos entre $5 \mathrm{cms}$ de altura y $8 \mathrm{cms}$ de diámetro) de los denominados "paredes finas", carenados o globulares, la mayoría de ellos con engobe de color oscuro y bruñidos. Procedente de la tumba 3 se recogió, antes de la excavación, la parte superior de un vaso campaniforme, y fragmento de otro, ambos decorados con incisiones. Junto a ellos se encontraban también cuatro puntas de tipo Palmela, además de un pequeño fragmento de posible puñal de cobre.

De la comparación entre las tumbas de Guadajira y la tumba circular de La Pijotilla se desprenden una serie de consideraciones que posibilitan el entendimiento del proceso ritual entre el III y II milenio a.n.e. en esta región. La primera de ellas se refiere a la pervivencia del enterramiento colectivo aunque, como ya se mencionó más arriba, el número de inhumaciones disminuye desde la etapa de los "tholoi" hasta los enterramientos individuales en cista. En este proceso el número de inhumaciones de Guadajira es sensiblemente inferior al de La Pijotilla. Las sepulturas cambian su estructura respecto a la etapa anterior, construyéndose mediante cámaras de planta circular y sin corredor, pero aún conservan antiguas características constructivas, como la cubierta en falsa cúpula de Guadajira 2. Respecto de los ajuares la presencia de cerámica campaniforme en las tumbas de ambos yacimientos permitiría datarlas en esta fase, pero mientras en La Pijotilla el estilo decorativo es puntillado geométrico en Guadajira es inciso.

12. El hallazgo tuvo una gran resonancia en Extremadura y en ella hubo de intervenir la policía que no pudo recuperar más que los vasos campaniformes.

13. A pesar de las prospecciones intensivas no se ha localizado ninguna otra tumba, aunque no se descarta la existencia de alguna posible tumba más en los lugares del cerro que han sufrido el arrastre y acumulación de tierras.

14. En uno de los huesos se encontraron indicios de haber estado en contacto con un objeto metálico. 
A excepción de la cerámica campaniforme el conjunto de recipientes de Guadajira presenta unas características morfométricas de gran homogeneidad, con una marcada reducción en el tamaño y similar a las que aparecen en los sepulcros del suroeste de la Edad del Bronce (García 1996).

Se trata de una cerámica que en su momento llamamos de "paredes finas" por ser ésta la denominación que mejor agrupaba a diversos tipos de factura cuidada y predominantemente reducida.

En el análisis de la secuencia cultural de la Cuenca Media del Guadiana se observó que este grupo iba aumentando en proporción numérica desde la fase precampaniforme hasta la Edad del Bronce. En La Pijotilla y Guadajira existe una clara tendencia por el uso de vasos de pequeño tamaño, sin embargo las diferencias se hacen notar en las formas y en el porcentaje.

Por otra parte mientras que en La Pijotilla hay un variado repertorio idólico, en Guadajira desaparecen los artefactos de carácter ideotécnico entre los componentes del ajuar, como sucede en las sepulturas del Bronce.

Las diferentes características existentes entre las tumbas de ambos yacimientos han hecho considerar Guadajira como una fase de tránsito entre el Calcolítico y Bronce, y posterior al Campaniforme, aunque no se dispone de cronologías absolutas. Resulta evidente que durante esta fase se asiste a un proceso de cambio en la estructura social que se deja sentir en los modos de enterramiento y que las tumbas de Guadajira suponen un paso más avanzado en la cadena de ese proceso. La cuestión que se plantea entonces se refiere a la cronología de esa fase y a si las tumbas de Guadajira suponen en realidad un modo de enterramiento generalizado en la región, o si se trata de una pervivencia aislada que aún conserva las prácticas anteriores del ritual colectivo frente al individual en cista o silo que sí comienza a generalizarse. Las evidencias parecen señalar que los tipos de enterramiento en tumbas circulares y los individuales en silos, fosas o covachas debieron coexistir en un momento determinado de la fase de tránsito, incluso es posible que las cistas comenzaran a implantarse a su vez en la periferia del territorio de Tierra de Barros. En el valle medio del Guadalquivir ocurre una situación similar, y en lugar de cistas se utilizan enterramientos en silos y covachas, coincidiendo cronológicamente con esta fase.

Así, las recientes excavaciones en el asentamiento del Castillo de Alange, cerca de Mérida, han mostrado una secuencia estratigráfica que abarca toda la Edad del Bronce. Este asentamiento supondría un cambio en el modelo poblacional de la zona, con el abandono del poblado campaniforme de La Palacina y la nueva ocupación en altura del vecino cerro del Castillo. El primer nivel, o fase Solana I, (Pavón 1994 y 1998) se identifica por un conjunto de formas cerámicas similar al de Guadajira y, según su excavador, correspondería a una datación entre 1800-1700 a.n.e ${ }^{15}$ A esta fase se adscribe también un enterramiento infantil en covacha (Pavón 1998: 23).

A poca distancia se encuentra el mencionado poblado de Palacio Quemado, con una fecha para la segunda fase de ocupación de $3520 \pm 100$ (1620 a.n.e.) y en cuyas proximidades se encuentra una necrópolis de cistas.

Algo más al sur, el poblado de Los Cortinales, sin presencia de campaniforme, ofrece una serie de evidencias artefactuales similares a las de Guadajira y Solana I y posiblemente a este asentamiento corresponda el grupo de cistas de Las Palomas (Gil-Mascarell y Rodríguez 1987; Rodríguez 1988).

Asimismo la última datación de 1770 a.n.e. para los enterramientos del tholos de Huerta Montero podría indicar la prolongación del uso de las cámaras colectivas hasta fechas bien avanzadas, en las que habría que incluir los enterramientos secundarios de Colada de Monte Nuevo (Schubart 1973)

En La Pijotilla también se encuentra presente el enterramiento individual. La posterioridad de este tipo de enterramiento frente al colectivo se constata de nuevo aquí de manera estratigráfica. La tumba T2 se vio afectada por la intrusión de una fosa de forma ochavada que rompió parte del arco circular. En su interior se hallaban dos cráneos (un joven masculino y un adulto femenino) con un solo cuenco como ajuar.

15. El nivel superior corresponde a Solana II (Bronce Pleno) y fue subdividido en A y B. El nivel IIB se fecha en $3600+/-80$ BP 
Otro enterramiento individual se situó entre los tholoi T1 y T3; reutilizando un viejo silo de almacén y varios silos con enterramiento individual se encuentran en el sector sur del yacimiento.

En la Pijotilla no se detecta una ocupación del Bronce, por lo que de acuerdo con la estratigrafía del Castillo de Alange, el final de este asentamiento se debió producir en la fase de tránsito, hacia 1700/1600 a.n.e.

\section{Registro artefactual}

\subsection{Cerámica}

Las crinologías extremeñas nos hacen suponer que el campaniforme no hace su aparición aquí hasta después del 2100 a.n.e.

Son pocos los asentamientos con campaniforme en Extremadura, pero como ya se comentó antes, la presencia o no de cerámica campaniforme no debe ser constitutiva de una considerable reducción en el número de asentamientos a inicios del II milenio a.n.e., sobre todo teniendo en cuenta las cronologías. Por otra parte la mayor cantidad de yacimientos extremeños se conoce a través de prospecciones y esto hace que disminuyan las posibilidades de detectar cerámica campaniforme en superficie. En la provincia de Badajoz el campaniforme apenas supone el $1 \%$ del conjunto de cerámica recogida en superficie, mientras que en excavaciones la proporción aumenta ligeramente: en el caso de un corte de 4 x 4 mts realizado en La Palacina el total de cerámica campaniforme alcanzaba una media de 1,4\%; en la estructura circular de Huerta de Dios tan sólo se halló un fragmento campaniforme entre la gran cantidad de material cerámico, lítico, o ídolos. Aunque no disponemos de datos estadísticos para los asentamientos de la provincia de Cáceres el porcentaje campaniforme parece incrementarse allí si atendemos a la presencia de 71 fragmentos campaniformes en un solo nivel de $2 \times 2 \mathrm{mts}$ del Cerro de la Horca. Es posible que esta proporción esté en consonancia con la de 5\% que se advierte en la región de Madrid (Blasco 1994). En el caso de la única tumba con enterramientos de esta fase, El Guadalperal ha proporcionado hasta diez ejemplares campaniformes con decoración incisa entre su ajuar (Fig. 7).

Acerca del registro funerario se puede concretar menos. A excepción de las noticias procedentes de Barbaño, en la que se menciona el hallazgo de piezas de oro y varias cerámicas campaniformes, la presencia de estos recipientes en el interior de las tumbas es muy exigua en la provincia de Badajoz: un vaso y un fragmento en T2 de La Pijotilla; medio vaso y un fragmento en T3 de Guadajira y un fragmento en el Dolmen de Lácara. Atendiendo a la clasificación tradicional de los estilos cerámicos del campaniforme se observa que el marítimo y puntillado geométrico se distribuyen preferentemente por el valle del Guadiana (Fig. 8). Así, en el poblado de Vista Alegre el único fragmento hallado era marítimo (Enríquez 1990: 148) y cerca del anterior, el asentamiento de La Palacina proporcionó estilo marítimo en la primera ocupación del sitio, y en el siguiente nivel se encuentran quince fragmentos, de los cuales "once se integran en el complejo marítimo y cuatro se relacionan en el complejo Palmela" o puntillado geométrico (Enríquez 1990: 187). En la tumba T2 de La Pijotilla se hallaron un vaso completo y un fragmento decorados con técnica de puntillado (Fig. 6). De La Palacina procede un cuenco con cuello marcado y una banda decorada con zigzag puntillada (Fig. 8, 10)(Enríquez 1990, Fig. 60, 10) cuya forma, dimensiones y decoración son idénticas a otro hallado en La Pijotilla (Fig. 9, 4), lo que avalaría la distribución de estos productos por el territorio de Tierra de Barros.

La estratigrafía del Cerro de la Horca aporta hasta ahora la mayor producción de cerámica campaniforme de Extremadura; de los 71 fragmentos cerámicos hallados en el nivel IIb (Fig.7,B), 31 son de estilo puntillado geométrico y 34 incisos Ciempozuelos, aunque los excavadores advierten de que este nivel se encontraba removido por los arados (González y Alvarado 1988). Entre ellos se menciona, además, la presencia de 
un vaso cordado, que suponemos de tipo $\mathrm{CZM}^{16}$ (González et alii 1988: 96). Este tipo, que hasta los años 80 limitaba su distribución al noreste peninsular y a un sólo ejemplar en el centro (Harrison 1977: 14) ha visto últimamente aumentar su presencia en la Meseta (Garrido 1995) y Extremadura.

En La Pijotilla (fig.9,1) se conocen dos fragmentos hallados en superficie (Hurtado y Amores 1985). Se trata de un curioso vaso que tiene la particularidad técnica de que no todas las líneas horizontales se realizan con impresión a cuerda, como en el caso de los ejemplares puros, sino que varias se hacen a peine; por otra parte el vaso está decorado con engobe a la almagra. La presencia de este ejemplar campaniforme en La Pijotilla hace que en la distribución peninsular del tipo lo consideremos como el más meridional y por tanto en el punto más alejado del foco originario europeo, de ahí posiblemente la hibridación e interpretación local que presenta. Aparte de las sugerencias que plantean las características técnicas de este vaso, conviene señalar la rápida implantación que el campaniforme tendría en Extremadura, si atendemos a la existencia en esta región de los estilos considerados más antiguos.

Por otra parte la mayor cantidad de información ha venido a confirmar que la distribución de la variante CZM tiene lugar por las mismas regiones que propusimos cuando en 1985 se trató el estudio de este tipo junto con la decoración de "pastillas repujadas". En el caso de la Meseta y Extremadura el campaniforme cordado se distribuye por las mismas zonas que la decoración mediante la técnica de "pastillas repujadas" y en algunos casos se observa la existencia de ambas decoraciones en un mismo yacimiento.

En el citado estudio de 1985 las pastillas repujadas señalaban una ruta de dispersión bastante lineal en su recorrido por la península: por un lado Cataluña y por otro País vasco, provincias de Logroño, Burgos, Ávila, Zamora, a las que se han venido a sumar nuevos hallazgos en las provincias de Madrid, Toledo, Cáceres y Badajoz, con lo que actualmente se completa la conexión entre las cuencas media del Tajo y la del Guadiana que antes quedaba vacía por falta de investigación.

En la provincia de Cáceres es particularmente importante la presencia de "pastillas repujadas" entre los artefactos cerámicos, procedentes tanto de prospecciones como excavaciones, hasta el punto que se encuentran en un $10 \%$ de los yacimientos documentados en la actualidad. En la de Badajoz, por el contrario, resulta más escasa, aunque se ha detectado en otros sitios de Tierra de Barros, pero no se conoce más al sur de esta comarca.

Las investigaciones realizadas en el área de Plasenzuela han aportado nuevos datos que nos aproximan mejor a la cronología propuesta en el trabajo anterior. Aquí la técnica decorativa se localiza en cuatro asentamientos durante una fase en la que aún no ha hecho aparición la cerámica campaniforme. Más concretamente aparece en el nivel IIa del Cerro de la Horca, datándose por cronología absoluta en $4215 \pm 100 \mathrm{BP}$. En el nivel superior II b, ya mencionado, en el que se encuentran varios estilos de campaniforme y el cordado entre ellos, el "índice de frecuencia [de pastillas repujadas] sube a medida que nos aproximamos a la superficie" (González et alii 1991: 14). De una cabaña de Cabrerizas, conteniendo recipientes con esta técnica decorativa y en la que no se detectó material campaniforme, procede la datación de 4060土85 BP (González et alii 1991:25). Estas dataciones vienen a coincidir con las obtenidas en La Pijotilla para la fase precampaniforme, como la de la tumba T3, de $4130 \pm 40 \mathrm{BP}$ y la de $4100 \pm 40 \mathrm{BP}$ de la estratigrafía del silo E4. Así pues la cronología de las pastillas repujadas en Extremadura se podría situar "grosso modo" entre el 2300 y el 2100 a.n.e., sin calibrar, estando en concordancia con las propuestas para estas cerámicas en el País Vasco entre el 2200 y el 2100 a.n.e. (Apellániz 1974) y las fechas absolutas de 2210 y 2150 a.n.e. del yacimiento languedociense de Beaussement (Guilaine 1976: 195), siendo el sureste francés donde la decoración de pastillas repujadas resulta más abundante y donde se conocen cronologías más antiguas.

El citado estudio (Hurtado y Amores 1985) venía a mostrar la sorprendente linealidad que en su distribución por la península presentaba esta técnica de decoración en pastillas repujadas, coincidiendo a grandes

16. Los autores lo mencionan únicamente como vaso cordado, sin descripción ni dibujo, paralelizándolo con el de La Pijotilla. 
rasgos (a pesar de la reducida documentación) con las localizaciones de la variante CZM campaniforme. Se apuntaba además que en algunos yacimientos las pastillas repujadas eran acompañadas por otra decoración realizada a peine con motivos lineales rectos u ondulantes, cuya coetaneidad se evidenciaba en la realización de ambas decoraciones sobre un mismo recipiente de Vilanova de Sâo Pedro (Paço y Jalhay 1945: Fig. 7) y en la aparición conjunta en la estratigrafía de La Pijotilla (Hurtado 1984; Hurtado y Amores 1985: 176)). Nuevos hallazgos en asentamientos de la provincia de Cáceres confirman esta asociación (González 1993)

Las estratigrafías coinciden, pues, en demostrar la anterioridad de las pastillas repujadas sobre el campaniforme cordado, aunque, como en el caso del Cerro de la Horca, estas decoraciones llegan a coexistir. Se sugirió entonces la existencia de unas "relaciones culturales" entre el sureste francés y el suroeste peninsular durante la fase precampaniforme, sin llegar a especificar si la regularidad en la línea de distribución señalaba rutas comerciales o si se trataba de un producto de importación. Parece evidente la mayor antigüedad de las pastillas repujadas en el territorio francés, por lo que la difusión de esta técnica decorativa en la península ibérica se produciría de norte a sur. Los recientes análisis físico-químicos efectuados a un grupo de cerámicas de La Pijotilla, Tierra de Barros y diversos yacimientos de la provincia de Cáceres manifiestan que la composición de las cerámicas resulta bastante homogénea entre grupos procedentes de zonas próximas. En La Pijotilla, estas cerámicas se contrastaron con otras comunes y con decoraciones varias, mostrando las pastillas repujadas una clara tendencia al agrupamiento frente al resto. De la comparación de estos con ejemplares cacereños se observa en varios diagramas una agrupación desigual en la composición, aunque también se aprecia homogeneidad entre los segundas (Estrada et alii 1997). Así pues, las diferencias entre las cerámicas de ambas zonas, relativamente próximas entre sí, descartaría el hecho de que la dispersión de pastillas repujadas se deba a importaciones y más bien indicarían que se trata de productos de fabricación local cuya distribución se realizaría por un territorio determinado, posiblemente desde un mismo lugar central.

La dispersión de la cerámica de pastillas repujadas a partir del foco francés consistiría, pues, en la propagación de una técnica decorativa, que se imita en diferentes regiones de acuerdo a un patrón ornamental. Su rápida difusión (como afirma Barceló "la información técnica viaja más que las gentes"(Barceló 1991: 77) estaría relacionada con la consideración de artículo de lujo, ya que el análisis de la composición de estas cerámicas indican un alto grado de calidad en su fabricación (Polvorinos et alii 1997). Ello posibilitaría considerar este tipo cerámico como un bien de prestigio, lo que supondría que ya hacia 2300-2200 a.n.e. se comienzan a establecer intercambios comerciales y a demandar productos de lujo a través de grandes rutas que posteriormente no haría más que seguir la cerámica campaniforme, como en el caso de la variante CZM. En apoyo de la hipótesis de intercambios comerciales no unidireccionales, sino mutuos, entre zonas tan alejadas, se cuenta con el hallazgo en el sureste francés, en Montmaurin, de un ídolo cilíndrico realizado en mármol local y figurando el tema oculado característico del sur peninsular ${ }^{17}$.

Por otra parte el conjunto del campaniforme inciso en Extremadura presenta similitudes formales y estilísticas con los grupos del valle del Guadalquivir, estuario del Tajo y la Meseta, sobre todo con ésta última y especialmente en el caso de la provincia de Cáceres debido a su proximidad. Los esquemas decorativos consisten principalmente en zigzags que alternan con trazos perpendiculares o líneas paralelas, zigzags impresos tipo "hoja de acacia", reticulados o impresiones "pseudoexcisas". En la Pijotilla son frecuentes los pequeños cuencos con profusa decoración en el interior, de claro matiz meseteño.

La aparición de estas cerámicas en Extremadura estaría relacionada con los contactos comerciales que se producirían entre poblaciones cercanas, en un proceso de difusión en cadena similar al observado en el caso de las "pastillas repujadas". Y aunque todavía no se han efectuado análisis en la composición de las cerámicas campaniformes de Extremadura, la observación de determinadas decoraciones en algunos

17. El hallazgo de este ídolo fue dado a conocer sucintamente por $\mathbf{J}$. Clottes en una noticia aparecida en la revista "Gallia Prehistoire" tomo 20, fasc.2 de 1977. 
ejemplares de La Pijotilla sugiere que se trataría de interpretaciones locales de modelos foráneos. A este respecto es también significativo el caso del ejemplar cordado con decoración a la almagra.

En los niveles con campaniforme se aprecia una disminución en el tamaño de los recipientes, predominan los cuencos hemiesféricos, se reduce el porcentaje de "platos" y aumenta el número de vasos de los denominados "paredes finas" que continuarán en la fase siguiente.

\subsection{Metalurgia}

Hasta ahora se conocen aproximadamente dos centenares de piezas metálicas en Extremadura, de las cuales el $85 \%$ corresponde al Calcolítico y de estas un $50 \%$ procede solamente del yacimiento de La Pijotilla (Hurtado y Hunt 1999).

El número de piezas mencionado es orientativo, porque en muchos casos la documentación consultada resulta muy escueta, limitándose los informantes a citar la presencia en el yacimiento de objetos metálicos o "metales", sin especificar, y, en otros casos, sin contabilizar el número de muestras. Por otra parte es muy escasa la información de restos metalúrgicos bien contextualizados. La gran mayoría de ellos (75\%) ha sido localizada en prospecciones de superficie. Del 25\% restante se puede llegar conocer el nivel de deposición y su cronología, pero en muy pocos casos de excavación en asentamientos se proporciona información sobre el contexto en el que fueron halladas las piezas.

La mayor cantidad de minas de cobre se encuentra al sur de la provincia de Badajoz, en las estribaciones de Sierra Morena. Tradicionalmente se ha considerado que es de aquí y concretamente de la zona de LlerenaAzuaga de donde procedería el grueso del material para la fabricación de artefactos metálicos. Recientemente y tras una observación más atenta se ha podido constatar la presencia, aunque escasa, de cobre en yacimientos de carácter polimetálico de Tierra de Barros, Mérida o Plasenzuela, con lo que la distancia a los centros de aprovisionamiento del mineral puede llegar a reducirse considerablemente. A este respecto se está comenzando a realizar análisis de isótopos de plomo para conocer la procedencia del metal y, como en el caso de La Pijotilla, algunas de las piezas analizadas parecen redundar en esta hipótesis, señalando su origen mineral hacia afloramientos próximos (Hunt 1998).

A pesar de ello poco se conoce sobre el proceso de manufactura del metal en los asentamientos calcolíticos extremeños. En la zona minera de Plasenzuela el ya citado Cerro de la Horca proporcionó en el nivel campaniforme un pequeño crisol con restos de fundición y mineral de malaquita junto a varios artefactos metálicos tales como láminas de cobre, punzones biapuntados, punta Palmela y cuchillo (González et alii 1991). La estratigrafía de este asentamiento, como la de Los Barruecos (Sauceda 1991) ponen de manifiesto que, con la llegada del campaniforme, aumenta el número de piezas metálicas sobre la fase precedente.

En la provincia de Badajoz, la zona de Llerena-Azuaga carece de suficientes excavaciones como para permitir extraer la información necesaria sobre las actividades minero-metalúrgicas en esta rica región minera. Sin embargo y a juzgar por los datos de prospecciones, las evidencias de manufactura metálica hasta ahora localizadas aparecen únicamente en asentamientos fortificados situados cerca de minas (El Pedrosillo y Los Palacios) y con cerámica campaniforme. En superficie se detectaron "escorias de metal" (Enríquez 1990: 76; Enríquez e Iñesta 1985: 24) con lo que existen indicios para pensar que en estos asentamientos también se realizarían procesos de fundición. En otro asentamiento, también fortificado, aunque sin campaniforme, de Risco del Cuervo se localizó una sierra, en Guijos de Matahaca un hacha de cobre y en Huerta de Dios, junto a cerámica campaniforme se menciona la existencia de un hacha y de metales, sin especificar (Enríquez 1990: 223). Las evidencias obtenidas hasta ahora indican, pues, que son las áreas mineras de Plasenzuela, Cáceres y Llerena-Azuaga, Badajoz, donde se encuentran los únicos indicios de producción metalúrgica en Extremadura. 
Como ya se mencionó anteriormente es en La Pijotilla donde se ha localizado el mayor número y variedad de objetos metálicos (supera el centenar) de toda la región extremeña (fig.10,F). La mayoría de los artefactos procede de superficie, posiblemente de los niveles correspondientes al campaniforme y removidos por la maquinaria agrícola. Pero existen algunos, aunque pocos, útiles y fragmentos metálicos procedentes de contextos estratigráficos de la fase anterior al campaniforme. De este momento, y a excepción del puñal de cobre hallado en la tumba T3, no se ha localizado ningún artefacto considerado como arma. Algunos instrumentos metálicos como hoces (el conjunto más numeroso), sierras, o hachas posiblemente correspondan a la fase precampaniforme, lo cual representaría la misma tendencia que se observa en los hallazgos de otros asentamientos calcolíticos extremeños, como El Lobo (Molina 1980), pero conviene tener en cuenta que los mismos tipos de instrumentos continúan apareciendo durante el campaniforme, como atestiguan los asentamientos de La Palacina o Huerta de Dios (Enríquez 1990: 223).

Respecto a las actividades de transformación metalúrgica en La Pijotilla se han encontrado algunas pocas muestras minerales cuyos análisis indican que se trata de dos tipos diferentes y quizás de procedencias distintas. Otros dos fragmentos cerámicos podrían haber formado parte de crisoles o moldes y varios goterones permiten inferir que en este asentamiento existieron evidencias de fundición, aunque relacionadas más probablemente con la fase de conversión en objetos, puesto que hasta ahora no han sido hallados restos de escorias (Hunt 1998).

A este respecto es interesante la existencia aquí de algunas piezas que podrían corresponder a lingotes de cobre por su aspecto macizo, sección gruesa y sin forma definida (Fig. 10, F9), con lo que resulta probable que dichas piezas correspondan a productos semielaborados que se comerciaran así para su traslado y posterior refundido y fabricación de instrumentos en lugares alejados de los centros metalúrgicos. Sin embargo no se han localizado moldes de fundición.

En los asentamientos extremeños el mayor número de artefactos metálicos aparece junto a cerámica campaniforme, de ellos los más numerosos son las puntas tipo Palmela, seguidos de punzones, sierras, cuchillos y cinceles. Mientras que las puntas Palmela se encuentran tanto en poblados como en tumbas, los característicos puñales de lengüeta están prácticamente ausentes en el registro habitacional y hasta el momento solamente han sido hallados en la superficie de La Pijotilla, sin que se conozca si proceden o no de contextos funerarios. El número de puñales es muy limitado incluso en el registro funerario, mencionándose un ejemplar en la supuesta tumba de Dehesa de la Pestaña, o Los Fresnos (Molina 1979), junto a otros objetos metálicos (Fig. 10, A), entre ellos "una punta de flecha de larga espiga" en la que no apareció cerámica campaniforme. Lo más probable es que la escasez de estos puñales esté en relación directa con la escasez que presentan los hallazgos de tumbas campaniformes en Extremadura.

Por otra parte conviene matizar, como vimos anteriormente, que la presencia de puntas Palmela en el interior de las tumbas se relaciona con contextos tardíos, en la fase de tránsito al Bronce, como demuestran las sepulturas de Guadajira (Hurtado y García 1996) y los enterramientos secundarios de Colada de Monte Nuevo (Schubart 1973) y Lácara (Almagro 1959) (Fig. 10, D y E).

Además de los mencionados puñales de lengüeta, en La Pijotilla se encuentran otros tipos de puñales diferenciados por la escotadura y por reforzamientos en el eje central; otro puñal de mayor tamaño presenta unas características más evolucionadas con un nervio longitudinal y un remache en el centro de la lengüeta que posiblemente corresponda a la última fase del asentamiento.

Resulta sugerente observar que los hallazgos de puñales, considerados bienes de prestigio y representativos del estatus social de ciertos individuos se encuentren en el asentamiento de mayor tamaño de la región, lo que podría reafirmar así un rango que se refleja en la jerarquización del territorio.

Junto a los hallazgos de objetos de cobre hay que añadir además los de oro. En Extremadura las localizaciones de piezas de oro elaboradas se reducen hasta ahora al entorno del río Guadiana, a Barbaño y La Pijotilla, mientras que la materia prima se encuentra en placeres auríferos del noroeste de Cáceres o en 
la zona portuguesa de Evora y Estremoz. La antes mencionada tumba de Barbaño, conteniendo recipientes campaniformes junto a diversas piezas áureas, confirma la asociación cronológica de ambos ítemes. En La Pijotilla se han localizado en superficie varias laminillas y otras cinco láminas cuadrangulares decoradas con triángulos rellenos de líneas oblicuas, todas ellas dentro del área delimitada por el foso interior en arco de círculo donde se encuentra la mayor concentración superficial de cerámica campaniforme del poblado.

La acumulación de artefactos metálicos en La Pijotilla indicaría el poder que determinados individuos o élites ostentarían en una estructura social cada vez más jerarquizada y que reforzarían simbólicamente mediante productos exóticos o extraños al propio territorio, como el cobre y el oro, entre otros ítemes de prestigio. De momento la propuesta no deja de ser hipotética ante la falta de evidencias empíricas en la región, especialmente en lo relativo al registro funerario; incluso la ausencia de ítemes metálicos en los pocos ejemplos disponibles de tumbas campaniformes, como la T2 de La Pijotilla, podría sugerir que en estos momentos el valor del metal como símbolo de estatus social no era todavía muy elevado (García y Hurtado 1997) y esta consideración podría extrapolarse al conjunto de la región atendiendo al reducido número de objetos metálicos hallados.

\section{Artefactos ideotécnicos}

En Extremadura los ídolos se encuentran al sur del Guadiana, sobre todo en Tierra de Barros y especialmente en el yacimiento de La Pijotilla, donde se concentra la mayor cantidad y variedad de representaciones idólicas no sólo de esta región sino también de la Península (Hurtado 1980 y 1995). Cabe citar los tipos de ídolos placas, betilos, tolvas, falanges, oculados o antropomorfos entre los más significativos que se encuentran presentes en el yacimiento para apreciar la importancia que estas representaciones tuvieron en este lugar. Uno de los tipos más característicos es una variante estilística del denominado "ídolo cilíndrico", de amplia difusión por el suroeste, cuya morfología difiere en Tierra de Barros por la forma rectangular o espatuliforme y sobre todo por la sección aplanada y no circular, además de la figuración de unas anchas cejas sobre el par de ojos (Fig. 11, A). En la estratigrafía de La Pijotilla este ídolo aparece en contextos precampaniformes, pero es evidente su continuidad en la fase siguiente como demuestran los hallazgos de la Dehesa de la Pestaña junto a un puñal de lengüeta (Molina 1978) o su localización en los niveles superficiales con cerámica campaniforme de la Estación de Zarza de Alange (Enríquez 1990: 143) y Palacio Quemado (Hurtado y Enríquez 1991: 86). Por ahora no se conocen en la región otros ejemplares fuera del área próxima al Guadiana.

De los contextos con campaniforme conocidos la citada tumba circular T2 de La Pijotilla proporcionó varios ídolos: dos ídolos placa, un ídolo tolva, dos falanges decoradas con el tema oculado (una de ellas con manos) y una falange lisa. Al sur, en el yacimiento con campaniforme de Huerta de Dios; aparecieron varios "ídolos de hueso largo" junto a dos ídolos placa, algunos betilos y falanges sin decorar, en un contexto que no se ha llegado a especificar, aunque parece descartado el funerario por no hallarse ningún hueso humano (Enríquez 1983). Pero no se conocen ídolos oculados en esta zona, solamente una figura humana de hueso o marfil hallada fuera de contexto en El Huertecillo de Llerena (Iñesta 1995), de la que trataremos más adelante.

En realidad la mayor parte de la representación idólica del suroeste se sintetiza en un sólo tema que es el de figurar unos ojos que de manera esquemática significaría la divinidad calcolítica. Esta iconología aparece plasmada sobre distintos soportes materiales y morfológicos como los cilindros, falanges o placas, pero la idea esencial resulta la misma: el símbolo de una deidad probablemente femenina (a juzgar por el atributo sexual que le acompaña en algunas representaciones). Y este esquema llegaría a estar tan asumido en la estructura mental de la sociedad calcolítica que incluso el soporte liso (un cilindro o falange sin decorar) tendría el mismo significado (Hurtado 1995). 
Otro tipo de representación frecuente en La Pijotilla es el antropomorfo o figura humana (Fig. 11, B), sin embargo existen pocos ejemplares de este tipo en el mediodía peninsular. Por otra parte en el mismo yacimiento aparecen claramente identificadas figuras masculinas y femeninas y fue aquí donde por primera vez se apreciaron estas diferencias de género (Hurtado 1980). En Extremadura se conocen varios ejemplares más: tres cabezas fragmentadas de caliza se encuentran depositadas en el Museo Geológico de Mérida (Porro 1995); uno procede de Rena (Fig. 11C), junto al río Guadiana (Hurtado y Perdigones 1983), y otro más del mencionado Huertecillo de Llerena (Iñesta 1995), éste último (fig.11,B2) muy similar al hallado en Marroquíes Altos de Jaén (Blanco 1962), en especial por tener ambos un objeto asido entre las manos ${ }^{18}$. La similitud morfológica entre el tipo de figura humana de la cuenca media del Guadiana y el del valle del Guadalquivir se manifiesta más evidente con los nuevos hallazgos de Llerena y La Pijotilla, lo que hace pensar en la vinculación del tipo entre una y otra región. Ninguna de las figuras extremeñas apareció en un contexto definido, por lo que resulta difícil determinar su cronología; el único dato disponible es que en Rena y el Huertecillo no se ha encontrado cerámica campaniforme. Sin embargo en otros lugares estas figuras parecen perdurar hasta inicios del II milenio a.n.e. El pozo en el que fueron hallados los dos ídolos de hueso de Valencina de la Concepción está fechado en $3910 \pm 110$ BP(Fernández y Oliva 1980), mientras que en Marroquíes Altos el ídolo se halló en una tumba de fosa, acompañado de una "jabalina" de cobre, que para algunos autores indica su carácter tardío (Blanco 1962, Almagro 1973: 251) ${ }^{19}$

A pesar, pues, de que en algunos lugares donde se encuentran los ídolos antropomorfos no aparece cerámica campaniforme todo parece indicar que estas representaciones corresponden a un momento avanzado del Calcolítico. Y con ello no se trata de afirmar que las figuras humanas hagan su aparición necesariamente durante la fase campaniforme. Se parte aquí de la hipótesis de que desde una perspectiva diacrónica el ídolo antropomorfo supone un estadio evolucionado respecto a otras representaciones idólicas. Sobre esta consideración observamos que a la tradicional representación esquemática de la divinidad oculada se opone otra de mayor naturalismo, en la que se identifica el carácter sexual de la figura. Y aunque entre las piezas halladas predominan las masculinas, también se encuentran otras femeninas, lo que puede significar que no se trata de un fenómeno de sustitución de un tipo de ídolo por otro, sino de la incorporación de una nueva forma de representación religiosa que convive con la anterior.

Por otra parte los artefactos ideotécnicos, como evidencias de la superestructura ideológica, pueden reflejar ciertos cambios que se producen en la esfera de la formación social. Así, la aparición de este nuevo "ídolo antropomorfo" testimoniaría en el ámbito ideológico la realidad que se hace sentir en la estructura social, cuando la figura del líder comenzara a consolidarse a fines del III milenio a.n.e. El hecho de que esta figura aparezca plasmada de una forma naturalista y no esquemática, indicaría el carácter novedoso de una representación plástica, no asumida aún por la comunidad, que necesitaría figurar de manera realista una nueva idea, la incorporación de la figura masculina a la categoría religiosa, hasta ahora eminentemente femenina. Con ello es posible que el liderazgo pretendiera legitimar su incipiente poder político a través de la religión, puesto que ambas categorías se encuentran íntimamente conectadas en las sociedades primitivas.

La hipótesis de que las figuras humanas reflejen el nuevo orden social elevando a la categoría religiosa un nuevo valor como es el del líder político-religioso, se vería apoyada por el objeto, probablemente la representación de un atributo de poder, que aparece asido entre las manos de las figuras de Llerena (especialmente éste), La Pijotilla y Marroquíes Altos. Por otra parte resulta sugerente que la mayoría de las figuras humanas de carácter masculino aparezcan asociados a asentamientos de gran extensión o centros nucleares de jerarquía

18. Al escribir esta líneas hemos tenido noticias del hallazgo en la superficie de La Pijotilla de una figura de hueso de características similares a las de Llerena y Marroquíes Bajos.

19. Recientemente se ha descubierto en las proximidades de la necrópolis un extenso poblado, el de Marroquíes Bajos, en una de cuyas últimas fases se han obtenido varias dataciones radiocarbónicas, todas ellas correspondientes al siglo XVIII a.n.e. (Hornos et alii 1998). 
territorial como Los Millares, Malagón, Marroquíes Altos, Valencina y La Pijotilla (sin que hasta el momento conozcamos las características de otros yacimientos y territorios circundantes donde se han hallado figurillas de este tipo, como Rena, en la provincia de Badajoz, o Esperilla en Cádiz ${ }^{20}$. Ello nos posibilita plantear la hipótesis de que las figuras humanas se sitúen en el marco de un sistema de liderazgo inserto en una organización social de tipo jerárquico comunalista y posiblemente relacionado con las funciones de reproducción ideológica (García y Hurtado 1997: 147), en el que esta representación encontraría su mejor acomodo en aquellos centros de poder político y religioso.

\section{Valoración}

A comienzos del III milenio a.n.e. la mayor densidad de ocupación humana se encuentra cercana a la actual frontera portuguesa, al norte y sur de la penillanura extremeña, más concretamente entre Aburquerque y Alcántara, y en los alrededores de Barcarrota. Las evidencias corresponden mayoritariamente a dólmenes y muy escasos poblados, a pesar de las reiteradas prospecciones llevadas a cabo (Oliveira 1994; Bueno y Balbín 1991).

En la segunda mitad del milenio el panorama cambia y las comunidades ocupan los territorios más fértiles de la penillanura, pero también otros de baja productividad potencial. Es durante la fase precampaniforme cuando se observa la mayor expansión del poblamiento por toda la región, aunque con diferente grado de intensidad, como se advierte en el alto porcentaje de asentamientos en la parte occidental de la cuenca media del Guadiana frente al muy bajo de la parte oriental.

Este proceso de ocupación estaría relacionado con la consolidación de la economía productiva excedentaria y la mejora tecnológica que igualmente se observa en otras regiones (García y Hurtado 1997: 146)

Habría que ver en la riqueza agrícola y el consiguiente excedente alimentario las causas de la densidad de asentamientos en Tierra de Barros. Este excedente habría permitido el desarrollo demográfico de una comunidad que, a partir de un foco o lugar originario, se disgregaría en pequeños poblados por un proceso de fisión. Se formaría así un territorio de carácter parental articulado en torno a un centro matriz, el cual acumularía las principales actividades económicas e ideológicas de esas comunidades dispersas (García 1996).

La marcada disposición lineal de fortificaciones en los límites de Tierra de Barros induce a pensar en un sistema de cierre utilizado fundamentalmente para la defensa de los excedentes acumulados en el interior del territorio y no para la única protección de los poblados situados en la zona de fricción. Lo más probable es que el cierre se estableciera para proteger el territorio de otras comunidades situadas al exterior, en terrenos más pobres, y de aquellos grupos de paso por la ruta que en sentido norte-sur conecta el valle del Guadalquivir con las cuencas medias de los ríos Guadiana y Tajo. A este respecto resulta sugerente la disposición en lugares estratégicos de poblados que aparecen alineados a lo largo de la ruta entre Sierra Morena y el vado del Guadiana cerca de Mérida (Hurtado 1995, Fig. 2).

Ello permitiría suponer que se trate de un espacio cohesionado, formado por unas comunidades solidarias cuyas relaciones sociales estarían basadas en la cooperación y redistribución de los medios de producción (García y Hurtado 1997: 147). La Pijotilla se erigiría, pues, en centro redistribuidor de un territorio jerárquico de base comunalista que ejerce el control sobre su consideración de núcleo matriz, lugar de referencia parental e ideológica, en donde la religión se constituiría en soporte ideológico sustancial. Es posible, pues,

20. Recientemente hemos tenido noticias más exactas sobre las figuras humanas depositadas en el museo de Geología de Mérida. Varias figuras proceden de Las Lomas, junto a Mérida, que ocupa una extensión de $300 \mathrm{~m}$ de diámetro. Otros tres asentamientos con figuras humanas son de menor tamaño. 
que la religión cumpliera una importante función como mecanismo regulador de las relaciones sociales en un territorio amplio y fuertemente jerarquizado (Hurtado 1995: 68).

Para algunos autores sería precisamente la importancia prestada en el Suroeste a la religión un signo de la debilidad de sus élites, las cuales necesitarían apoyarse en ella para consolidar su poder (Díaz-Andreu 1993: 252).

Y es con relación a los inicios de la complejidad social donde conviene situar la aparición de representaciones de figurillas humanas, las cuales consideramos cobrarían sentido en el momento en que se empiezan a manifestar diferencias en la escala social. Cada organización social debe tener su correspondencia en la escala ideológica. La hipótesis de la aparición de estas figuras se relacionaría precisamente con los cambios que se hacen sentir en la denominada sociedad jerarquizada comunalista (ver discusión en García 1996; García y Hurtado 1997), en un intento de elevar a la categoría religiosa la figura de un personaje masculino, la del Gran Hombre o líder político-religioso, que ahora comienza a tomar posición en el orden jerárquico. Las figuras de Llerena y La Pijotilla portando un objeto entre las manos, probablemente un hacha como símbolo de poder y la localización de la mayor parte de las piezas de este tipo en centros de control de territorios jerarquizados, parecen apoyar el significado de esta nueva expresión ideológica.

Con la llegada del campaniforme nos encontramos, pues, que algunas de las características que se habían venido adscribiendo a esta fase tendrían su origen en un momento anterior. En el ámbito cronológico cabe mencionar la pronta introducción del campaniforme en la región extremeña puesto que se encuentran presentes los tipos de cerámica campaniforme más antiguos.

La presencia del tipo AOC en Extremadura indicaría el paralelismo existente en la distribución por la península ibérica entre esta cerámica campaniforme y las "pastillas repujadas". Las cronologías absolutas muestran la mayor antigüedad de la decoración de pastillas repujadas sobre el campaniforme y la rápida difusión peninsular de esta técnica decorativa a partir del sureste francés. Ello puede significar que previa a la llegada del campaniforme existirían redes comerciales de larga distancia por las cuales circularían los nuevos productos. Ahora bien, los análisis efectuados a estas cerámicas (Polvorinos et alii 1997) muestran que no se trata de productos importados, sino de la transmisión de unos conocimientos en la técnica de decorar la cerámica, que se difunden de forma encadenada por áreas próximas entre sí y cuya fabricación y posterior distribución por un determinado territorio se realizaría desde un centro productor. La calidad de fabricación de esta cerámica posiblemente induciría a pensar que se trata de un producto de lujo. A pesar de esta consideración no es frecuente encontrar cerámica de "pastillas repujadas" entre el ajuar funerario (aunque son muy escasas las evidencias de tumbas), como ocurre con el campaniforme, a excepción del tholos de El Guadalperal donde hay, además, cerámica campaniforme (Leisner y Leisner 1960).

Si lo que hasta ahora se constata a lo largo de esa franja de comunicación entre el sur de Francia y el suroeste peninsular es la distribución de una técnica de decoración cerámica es lógico pensar que existieran otros motivos de índole comercial y de mayor interés para el establecimiento de esa ruta que la mera transmisión de unos conocimientos de decoración. La cuestión es qué productos e ideas constituirían la base de la interacción entre zonas tan alejadas.

El mecanismo de distribución "en cadena" de la mencionada técnica decorativa nos hace pensar que pudo ocurrir de forma similar en el caso de la cerámica campaniforme. El vaso de tipo AOC de La Pijotilla, de claro origen foráneo, es de fabricación local, incluso incorpora engobe a la almagra (asociada a la tradición ornamental del sur peninsular) en la decoración (Hurtado y Amores 1985). Y en algunas regiones, como en la de Madrid, donde se han efectuado análisis físico-químicos a la cerámica campaniforme se observa el carácter indigenista y local de su fabricación (Blasco 1994: 123). Parece evidente que habrá que buscar alternativas a la explicación de cómo se distribuyen estos productos de lujo, ya que por ahora todo indica que, al menos, en su mayor parte, no es un conjunto de productos manufacturados los que circularían a través de las rutas comerciales, sino técnicas, motivos o estilos decorativos los que se transmiten. En el caso de la cerámica resulta obvio admitir la facilidad con la que se puede imitar un recipiente por cualquier ceramista 
de este período sin necesidad de adquirir fuera toda la producción. La similitud de técnicas y estilos y lahomogeneidad que en paralelismo cronológico se produce en diferentes regiones señalan, efectivamente, la continua y rápida conexión de conocimientos que debió existir entre ellas. La transmisión de estos conocimientos se traduciría posteriormente en variaciones locales de estilos cerámicos.

Respecto a la metalurgia extremeña resulta patente el incremento de la producción durante la fase campaniforme. La introducción de nuevos objetos metálicos, como puñales de lengüeta, puntas, leznas biapuntadas y adornos de cobre, además de piezas de oro responde a modelos generalizados en muchas regiones, cuyo mecanismo de difusión se debió producir conjuntamente con el de la cerámica. Sin embargo, la tecnología metalúrgica y sobre todo la materia prima no se sitúan al mismo nivel de disposición que la cerámica. Es lógico pensar que la adquisición, al menos del mineral de cobre, fuera debida a la importación por parte de aquellas comunidades que no poseyeran en sus territorios esta materia prima y que incluso fueran importados los artefactos metálicos. Pero un análisis más detallado de territorios y asentamientos concretos, como el de Tierra de Barros, mostraría que en otros ejemplos el mineral no procede necesariamente de lugares alejados, de los tradicionalmente considerados focos metalúrgicos, sino que en sus proximidades es posible encontrar el mineral suficiente para abastecer, al menos parte si no todas, las demandas de ese territorio.

Por otra parte, en el caso de que el mineral sea importado, se suelen observar en uno o varios asentamientos de ese territorio indicios de algún paso en la cadena de producción metalúrgica a través de los cuales se puede inferir la fabricación final de objetos metálicos en el mismo lugar. En este caso es posible que la distribución de artefactos metálicos por el territorio se realizara a partir de un centro distribuidor.

La fase campaniforme en Extremadura al final del III milenio a.n.e. no supondría cambios sustanciales, drásticos, en la organización social de base comunalista, aunque sí haría aumentar las diferencias, posiblemente en el ámbito de las relaciones interclánicas. Estas se manifiestan en las evidencias funerarias, tanto en los contenedores como en los contenidos. La tumba campaniforme de La Pijotilla mantiene el ritual colectivo de enterramiento, aunque en considerable menor número de inhumaciones y difiere respecto a los tholoi en su estructura, ahora simplificada y reducida al menor esfuerzo constructivo.

Este carácter reductor es el que parece hacerse sentir en otros ámbitos espaciales. En La Pijotilla, según la distribución de ítemes en superficie (Hurtado 1999) el asentamiento se constriñe durante el campaniforme a la mitad del tamaño original; se abandona el recinto circular que forma el foso exterior, el cual debía suponer un enorme esfuerzo colectivo en su mantenimiento, y se construye un foso menor en arco de círculo.

En cuanto al territorio es difícil pronunciarse, ya que existen pocos yacimientos con campaniforme, la mayor parte de la información procede de prospecciones superficiales y faltan series de dataciones absolutas. $\mathrm{Si}$ atendemos exclusivamente a los indicadores cerámicos y a determinar el poblamiento territorial por la presencia/ausencia de material campaniforme, nos encontraríamos con una región casi vacía de asentamientos, lo cual no correspondería en absoluto a la realidad. La cerámica campaniforme es muy escasa en Extremadura y esta escasez no debe erigirse en paradigma de la determinación del poblamiento de un territorio, ni su ausencia ser utilizada como referente cronológico (ver discusión en Hurtado y García 1996).

Pero si atendemos a la información del área de Plasenzuela quizás sí se produjera un moderado despoblamiento de ese territorio a partir del campaniforme. Y este despoblamiento se hace más evidente y generalizado en la fase de tránsito a la Edad del Bronce.

Hasta entonces, al menos en Tierra de Barros, hemos de suponer que continúa existiendo la cohesión social entre las comunidades integradas en el territorio, mientras que se debieron incrementar las diferencias interterritoriales, como muestran los incendios que tuvieron lugar en los poblados fortificados del límite fronterizo.

Hacia 1600 a.n.e. se produciría el final de la cohesión de un territorio constituido parentalmente, en el que las élites han perdido la capacidad de aglutinar a las comunidades que la integraban y en el que desaparece la expresión ideológica que servía de apoyo. 
VICTOR HURTADO PÉREZ

\section{BIBLIOGRAFÍA}

ALMAGRO, A. (1959): "Excavaciones en el sepulcro de corredor megalítico de Lácara, Mérida (Badajoz)", Revista de Estudios Extremeños. Mayo-Agosto.

ALMAGRO, Ma.J. (1973): Los ídolos del Bronce I Hispano Biblioteca Praehistorica Hispana XII. Madrid. APELLÁNIZ, J.M. (1974): "El grupo de Los Husos durante la Prehistoria con cerámica en el País Vasco", Estudios de Arqueología Alavesa 7.

BARCELÓ, J.A. (1991): Arqueología, Lógica y estadística. Un análisis de las estelas de la Edad del Bronce en la Península lbérica. Barcelona.

BLANCO, A. (1962): "Die Altesten plastichen Menschen-Darstellung der Iberischen Halbinsel", Madrider Mitteillungen, 3: 11-20.

BLASCO, C. (Ed.) (1994): "El horizonte campaniforme de la región de Madrid en el centenario de Ciempozuelos". UAM. Madrid.

BUENO, P. y BALBÍN, R. (1991): "El proyecto arqueológico Valencia de Alcántara: El Jardinero y yacimientos megalíticos de la comarca de Valencia de Alcántara, Cáceres”, Extremadura Arqueológica II. Mérida-Cáceres.

ENRÍQUEZ, J.J. (1983): “Dos ídolos sobre hueso largo procedentes de Huerta de Dios”, Trabajos de Prehistoria, 40: 293-306.

ENRÍQUEZ, J. J. (1990): El Calcolítico o Edad del Cobre de la Cuenca Extremeña del Guadiana: Los poblados. Museo Arqueológico Provincial de Badajoz. Publicaciones 2.

ENRÍQUEZ, J. J. e IÑESTA, J. (1985): "Notas sobre los poblados calcolíticos de la comarca de Llerena", Homenaje a Cánovas Pesini. Diputación de Badajoz.

ENRÍQUEZ, J. J. e IÑESTA, J. (1995): “El poblado prehistórico de El Huertecillo en Llerena", Revista de Estudios Extremeños T. LI, n I 1995: 9-24.

ESTEBAN, J. y SALAS, J. (1988): "1 ${ }^{a}$ campaña de excavaciones en el Castro de Santiago del Campo (Cáceres)", Extremadura Arqueológica I: 129-142.

ESTRADA, F; ONTALBA, M.A.;RESPALDIZA, P.; PÉREZ, P. y HURTADO, V. (1997): "Técnicas nucleares aplicadas al estudio de cerámicas del Calcolítico extremeño", Cuadernos de Prehistoria de la Universidad de Granada (e.p.).

GALÁN, E. y MARTÍN, A. (1991-92): “Megalitismo y zonas de paso en la cuenca extremeña del Tajo", Zephyrus XLIV-XLV: 193-206.

GARCÍA SANJUÁN, L. (1996): Un análisis de los orígenes de la estratificación social en la Prehistoria del Suroeste de la Península Ibérica. Tesis doctoral inédita. Universidad de Sevilla.

GARCÍA SANJUÁN, L. y HURTADO, V. (1997): "Los inicios de la jerarquización social en el Suroeste de la Península Ibérica (c.2500-1700 ane). Problemas conceptuales empíricos", Homenaje a la Dra. Gil Mascarell. Saguntum 30: 135-152.

GARRIDO, R. (1995): "El campaniforme en la Meseta sur: Nuevos datos y propuestas teóricas", Complutum 6: 123-151.

GIL-MASCARELL, M.; RODRÍGUEZ, A. (1987): "El yacimiento calcolítico de Los Cortinales en Villafranca de los Barros (Badajoz)", Homenaje a D. Fletcher. Archivo de Prehistoria Levantina XVII: 123-145. GÓMEZMORÓN, A.; POLVORINOS, A.; ONTALBA, M.A.; RESPALDIZA, M.A.; HURTADO, V.; KISS, A.Z.; BORBELINE-KISS, I. (1997): "Estudio arqueométrico de cerámicas calcolíticas del yacimiento de La Pijotilla (Badajoz, España)" 4th European Meeting of Ancient Ceramics. Andorra, 1997 (e.p.). GONZÁLEZ, A. (1993): "Evolución, yacimientos y secuencia en la Edad del Cobre en la Alta Extremadura", $1^{\circ}$ Congreso de Arqueologia Peninsular. Trabalhos de Antropologia e Etnologia, XXXIII: 238-256. Porto. 
GONZÁLEZ, A (1998): "Poblamiento de la Edad del Cobre en la Alta Extremadura: Sector de Valdecañas (Cáceres)". En R. Balbín y P. Bueno (eds), II Congreso de Arqueología Peninsular. Tomo II Neolítico, Calcolítico y Bronce. Fundación Rei Afonso Henriques.

GONZÁLEZ, A y ALVARADO, M. (1988): "El poblado calcolítico del Cerro de la Horca-Plasenzuela

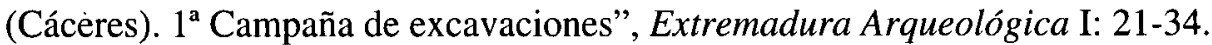

GONZÁLEZ, A y QUIJADA, D. (1991): Los orígenes del Campo Arañueloy la Jara cacereña. Navalmoral de la Mata .

GONZÁLEZ, A.; CASTILLO, J. y HERNÁNDEZ, M. (1991): "La secuencia estratigráfica en los yacimientos calcolíticos del área de Plasenzuela (Cáceres)", I Jornadas de Prehistoria y Arqueología en Extremadura (1986-1990). Extremadura Arqueológica II: 11-26.

GONZÁLEZ, A; ALVARADO, M.; MUNICIO, L. y PIÑÓN, F. (1988): "El poblado de El Cerro de la Horca (Plasenzuela, Cáceres). Datos para la secuencia del Neolítico tardío y la Edad del Cobre en la Alta Extremadura" Trabajos de Prehistoria 45, 87-102.

GUILAINE, J. (1976): Premiere bergers et paysans de l'Occident mediterranén. Mouton-Paris-La Haye. HARRISON, R. (1977): The Bell Beaker cultures of Spain and Portugal. Cambridge.

HORNOS, F., ZAFRA, N. Y CASTRO, M. (1998): "La gestión de una zona arqueológica urbana: la experiencia de investigación aplicada en Marroquíes Bajos Jaén)", PH. Boletín del Instituto Andaluz de Patrimonio Histórico VI, 22: 82-91.

HUNT, M. (1998): Minería y metalurgia prehistóricas en Andalucía Occidental. Tesis doctoral inédita. Universidad de Sevilla.

HURTADO, V. (1984): El yacimiento de La Pijotilla (Badajoz). Estudio de relaciones culturales. Tesis doctoral inédita. Universidad de Sevilla.

HURTADO, V.(1985): "Excavación de una sepultura circular de la Edad del Bronce en Guadajira", Homenaje a Cánovas Pesini. Badajoz.

HURTADO, V. (1986): "El Calcolítico en la Cuenca Media del Guadiana y la necrópolis de la Pijotilla" Actas de la Mesa Redonda sobre Megalitismo peninsular (Madrid 1984): 51-75. Madrid.

HURTADO, V. (1991): "Informe de las excavaciones de urgencia en la Pijotilla. Campaña de 1990", I Jornadas de Prehistoria y Arqueología en Extremadura (1986-1990). Extremadura Arqueológica II: 45-68.

HURTADO, V. (1995): "Interpretación sobre la dinámica cultural en la Cuenca Media del Guadiana (IV-II milenio ane.)". Homenaje a la Dra. Milagros Gil-Mascarell. Extremadura Arqueológica V: 53-80.

HURTADO, V. (1999e.p.): "Surface survey analysis of Copper Age site of La Pijotilla (Spain)", Populus Project. Extracting meaning from plougsoil assemblages. Siena 1995.

HURTADO, V. y AMORES, F. (1985): "Estudio de relaciones culturales a través de fósiles directores en La Pijotilla (Badajoz)", Actas de las II Jornadas de Metodología y Didáctica de la Historia. Cáceres: 169-194.

HURTADO, V. y ENRÍQUEZ, J. J. (1991): "Excavaciones en Palacio Quemado (Alange, Badajoz). Informe preliminar", I Jornadas de Prehistoria y Arqueología en Extremadura (1986-1990). Extremadura Arqueológica II: 69-88.

HURTADO, V. y GARCÍA, L. (1994): "La necrópolis de Guadajira (Badajoz) y la transición a la Edad del Bronce en la Cuenca Media del Guadiana", Spal 3: 95-144.

IÑESTA, J. (1995): "Un hallazgo excepcional: el ídolo de Llerena", Revista Fiestas Patronales 95. Llerena: 11-14.

MARTÍN, J.C. y MIRANDA, J.M. (1988): "El poblado calcolítico de Valencina de la Concepción (Sevilla): una revisión crítica" Cuadernos de Prehistoria y Arqueología de la Universidad Autónoma de Madrid 15, 37-67.

MELIDA, J.R. (1925): Catálogo Monumental de España. Provincia de Badajoz. Madrid. 
MOLINA, L. (1980): "El poblado del Bronce I El Lobo (Badajoz)", Noticiario Arqueológico Hispánico 9: 92-127.

MOLINA, L. (1978): "La colección de ídolos-cilindro del Museo Arqueológico Provincial de Badajoz procedentes del sepulcro megalítico de Los Fresnos", Revista de Archivos, Bibliotecas y Museos LXXXI, 3: 671-677.

MOLINA, L. (1979): "El extraordinario ajuar del sepulcro megalítico de Los Fresnos", Revista de Estudios Extremeños 35, 3: 631-642. Diputación Provincial de Badajoz.

MUÑOZ, K., GARCÍA, T. e IZQUIERDO, D. (1995): “Aportaciones al estudio de la Edad del Cobre en la Cuenca Media del río Tajo", Boletín del Seminario de Estudios de Arte y Arqueología, LXI: 31-50

OLIVEIRA, J. (1994): Sepulturas megalíticas del término municipal de Cedillo. Ayuntamiento de Cedillo.

PAÇO, A. y JALHAY, E. (1945): "El castro de Vilanova de San Pedro", Actas y Memorias de la de la Sociedad Española de Antropología, Etnología y Prehistoria. Tomo XX. Madrid.

PAVÓN, I. (1994): Aproximación al estudio de la Edad del Bronce en la Cuenca Media del Guadiana: La Solana del Castillo de Alange (1987). Inst. Cultural Brocense. Cáceres.

PAVÓN, I. (1998): "El cerro del Castillo de Alange (Badajoz). Intervenciones arqueológicas (1993)", Memorias de Arqueología Extremeña 1.

POLVORINOS, A.; GÓMEZ, A. y HURTADO, V. (e.p.): "Análisis morfométrico de cerámicas calcolíticas del yacimiento de La Pijotilla (Badajoz)" $4^{\text {th }}$ European Meetings of Ancient ceramics. Andorra.

PORRO, T. (1995): "Una nueva sala para la colección de Prehistoria de la Comarca de Mérida" Revista de Arqueología, 166.

RODRÍGUEZ, A. (1988): "Los Cortinales. Un yacimiento calcolítico en Villafranca de los Barros (Badajoz)", Extremadura Arqueológica I: 55-68.

ROVIRA, S. MONTERO, I. y CONSUEGRA, S. (1997): Las primeras etapas metalúrgicas en la Península Ibérica. I. Análisis de materiales. Fundación J. Ortega y Gasset. Madrid.

SAUCEDA, M.I. (1991): "La secuencia cultural de Los Barruecos, Malpartida de Cáceres (Cáceres)", I Jornadas de Prehistoria y Arqueología en Extremadura (1986-1990). Extremadura Arqueológica II: $27-44$.

SCHUBART, H. (1973): “Tholos-Bauten von Colada de Monte Nuevo bei Olivenza”, Madrider Mitteilungen 14. 


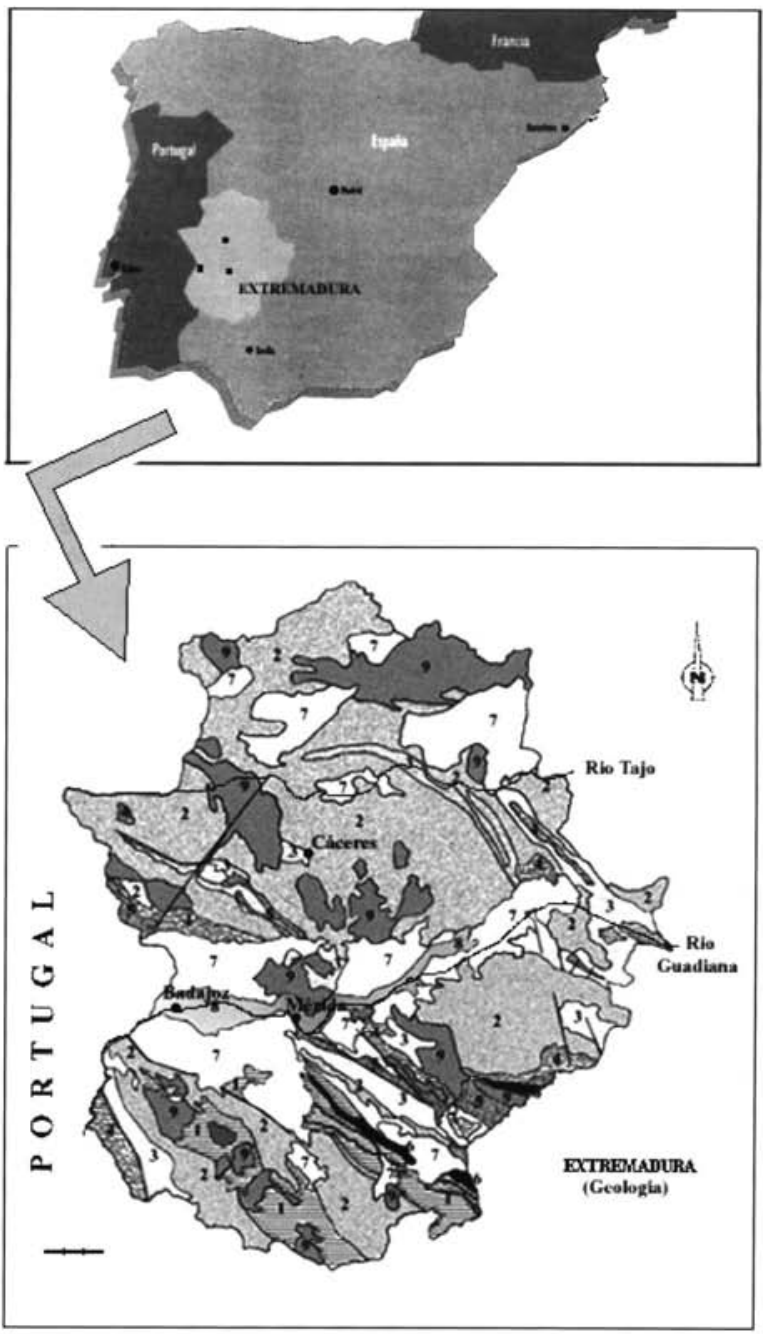

Figura 1 


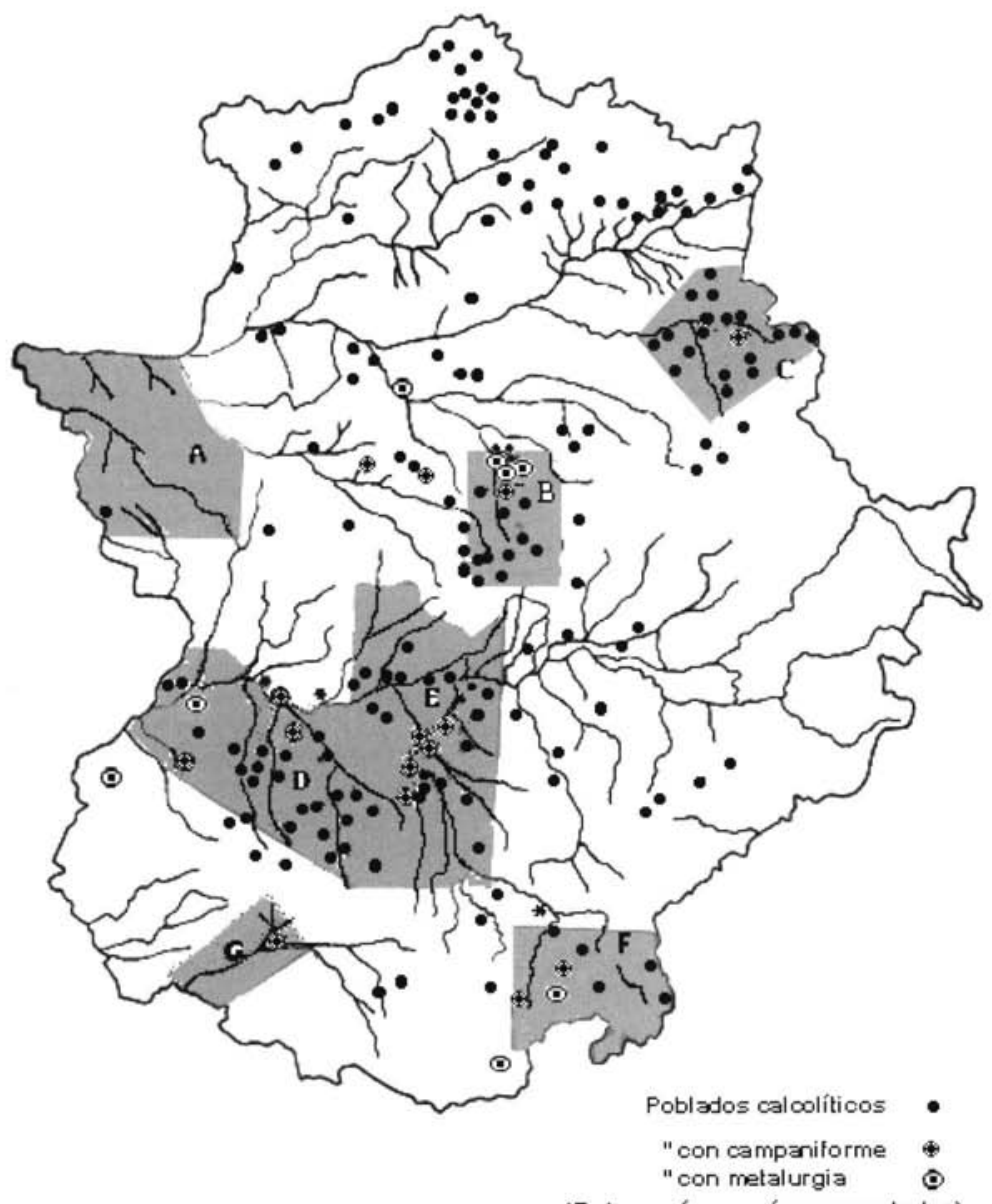

(Entrama áreas más prospectadas)

Distribución de los asentamientos calcolíticos en Extremadura

Figura 2 


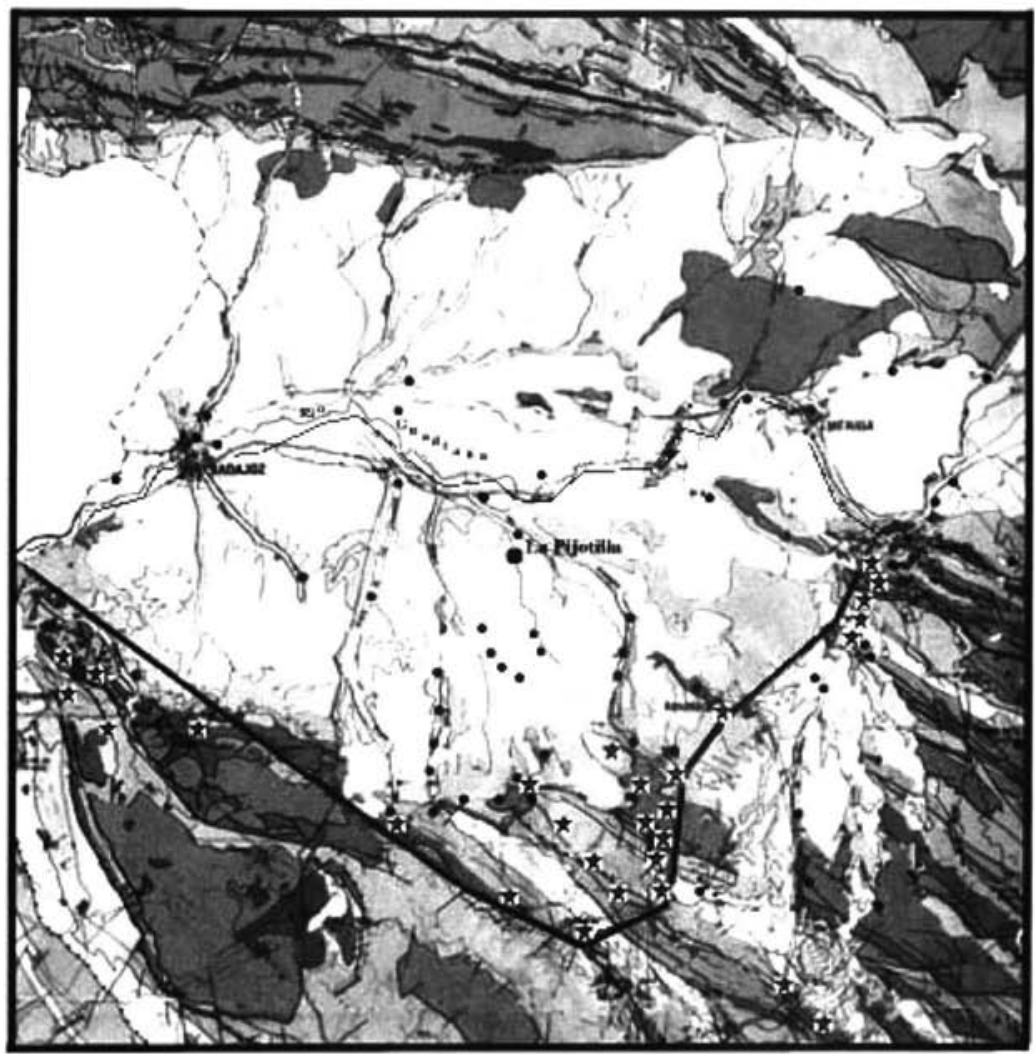

- Poblados en llane

* Poblados fortificados

Línea: Posible límite territorial

Distribución de asentamientos en la penillanura occidental

Figura 3 


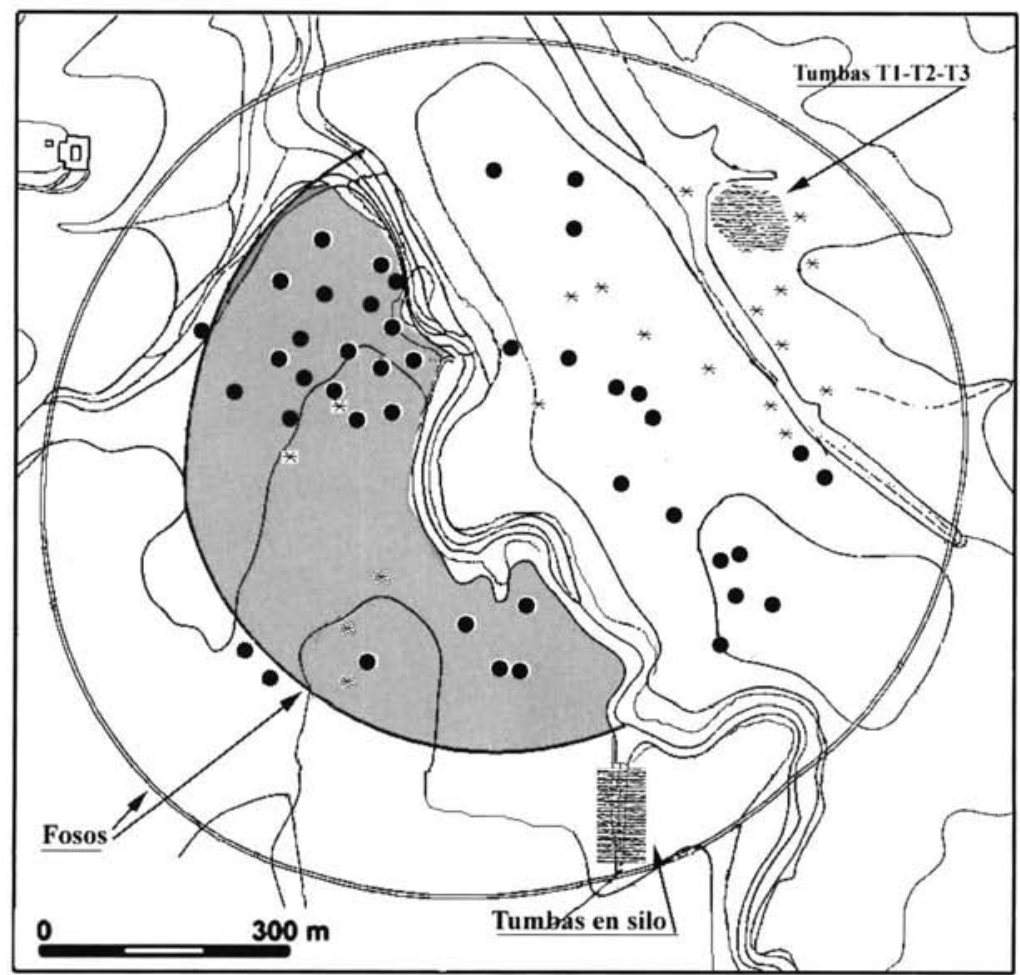

Plano del asentamiento de La Pijotilla con la ubicación de los fosos, tumbas, ídolos (๑) y objetos metálicos (*)

Figura 4 


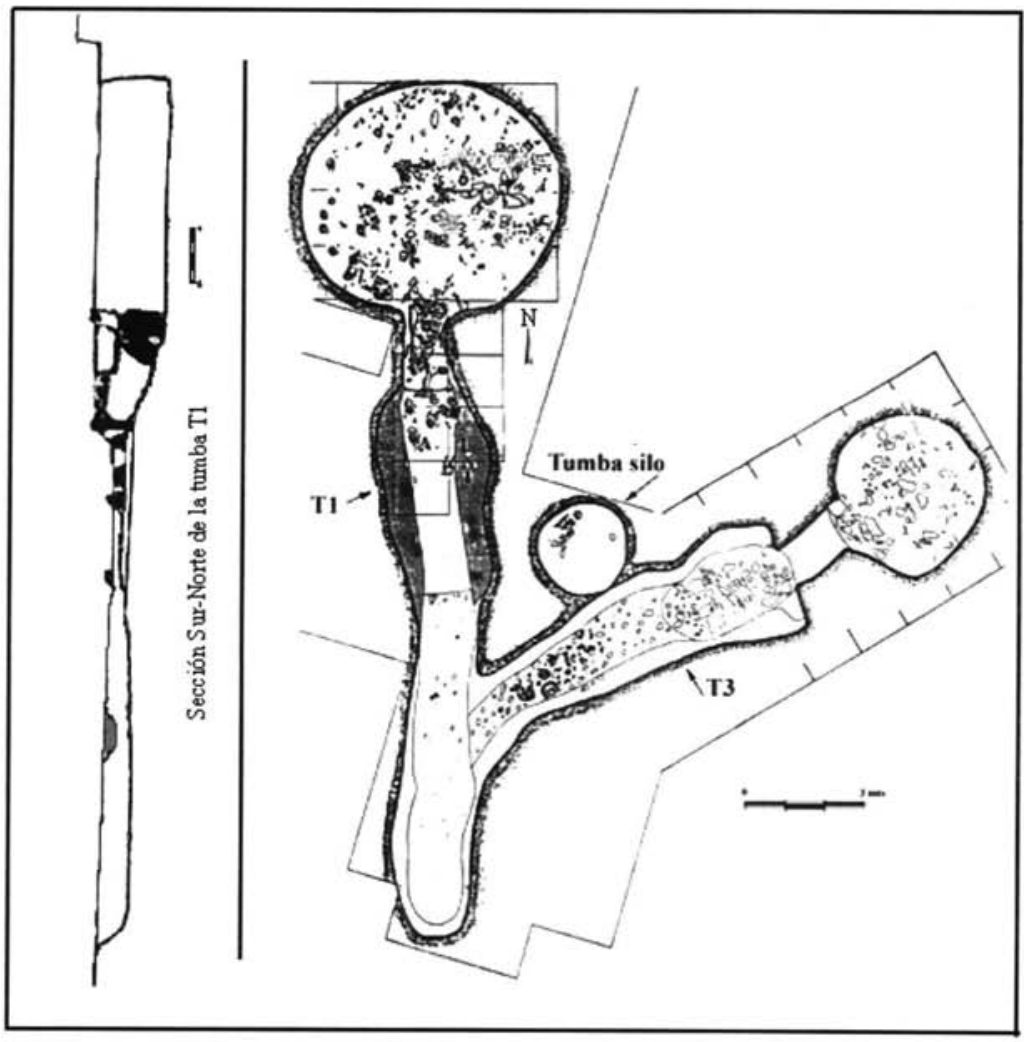

Figura 5 

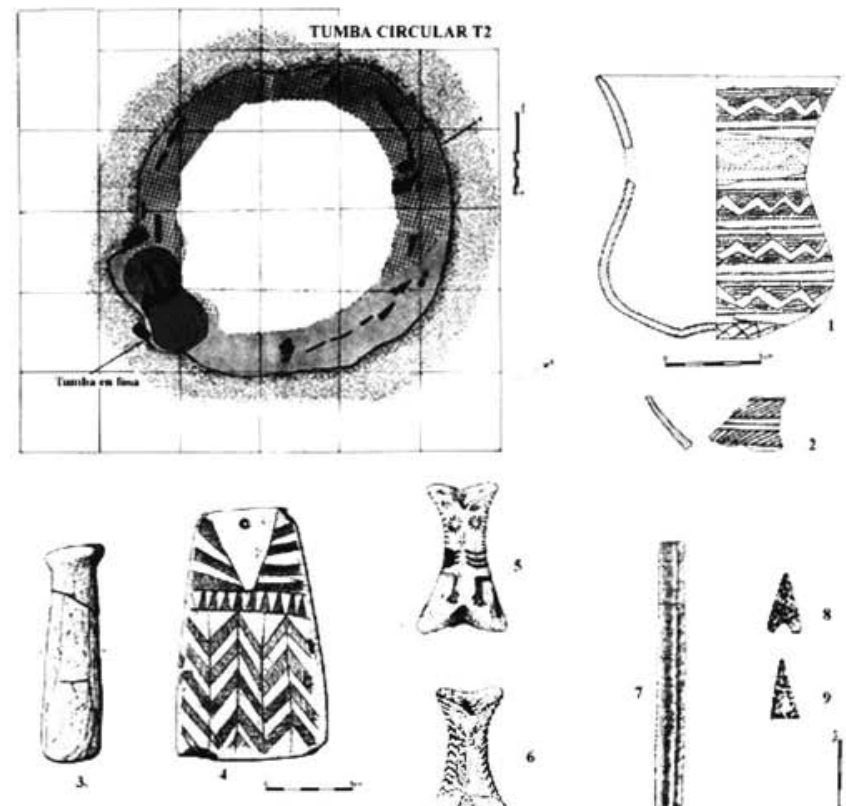
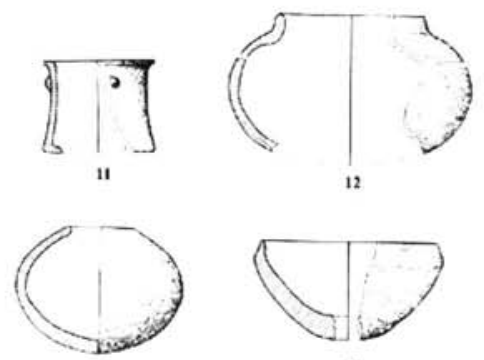

13

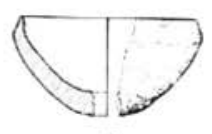

14

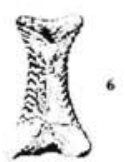

$\because: \div: \bigodot_{\infty}:::$
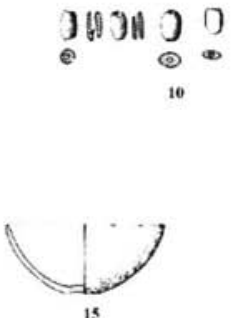

Figura 6 

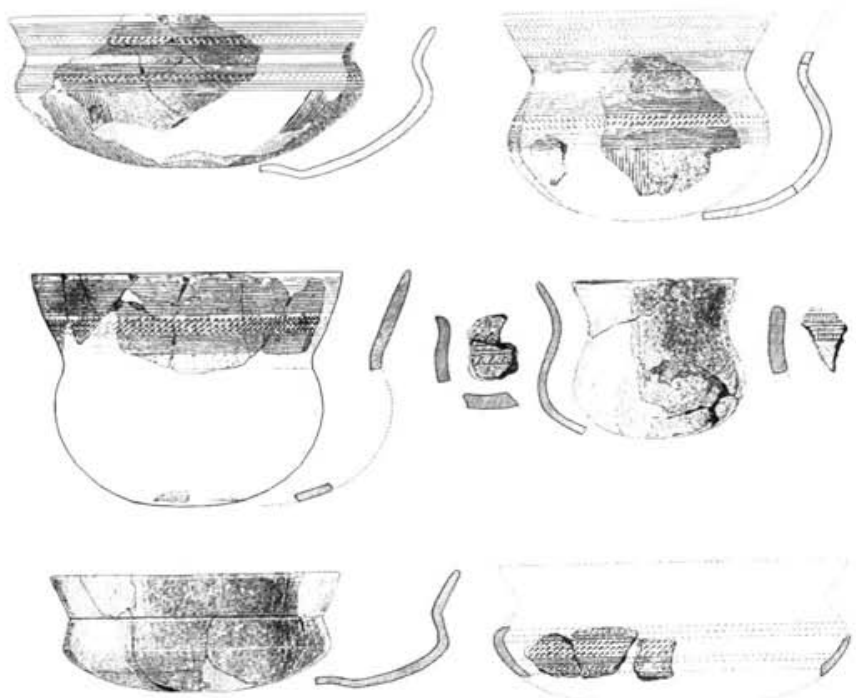

B
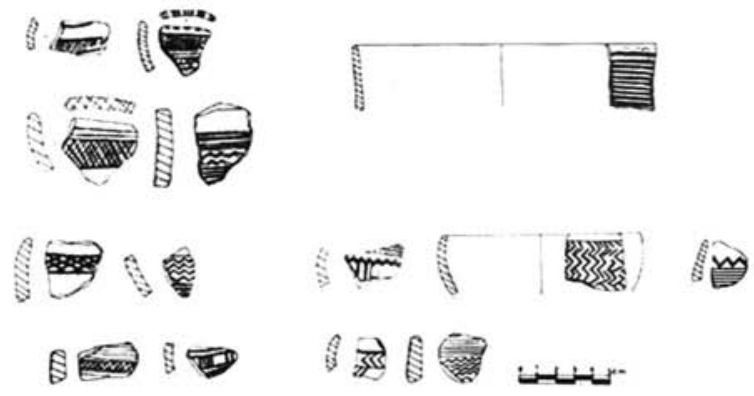

Figura 7 


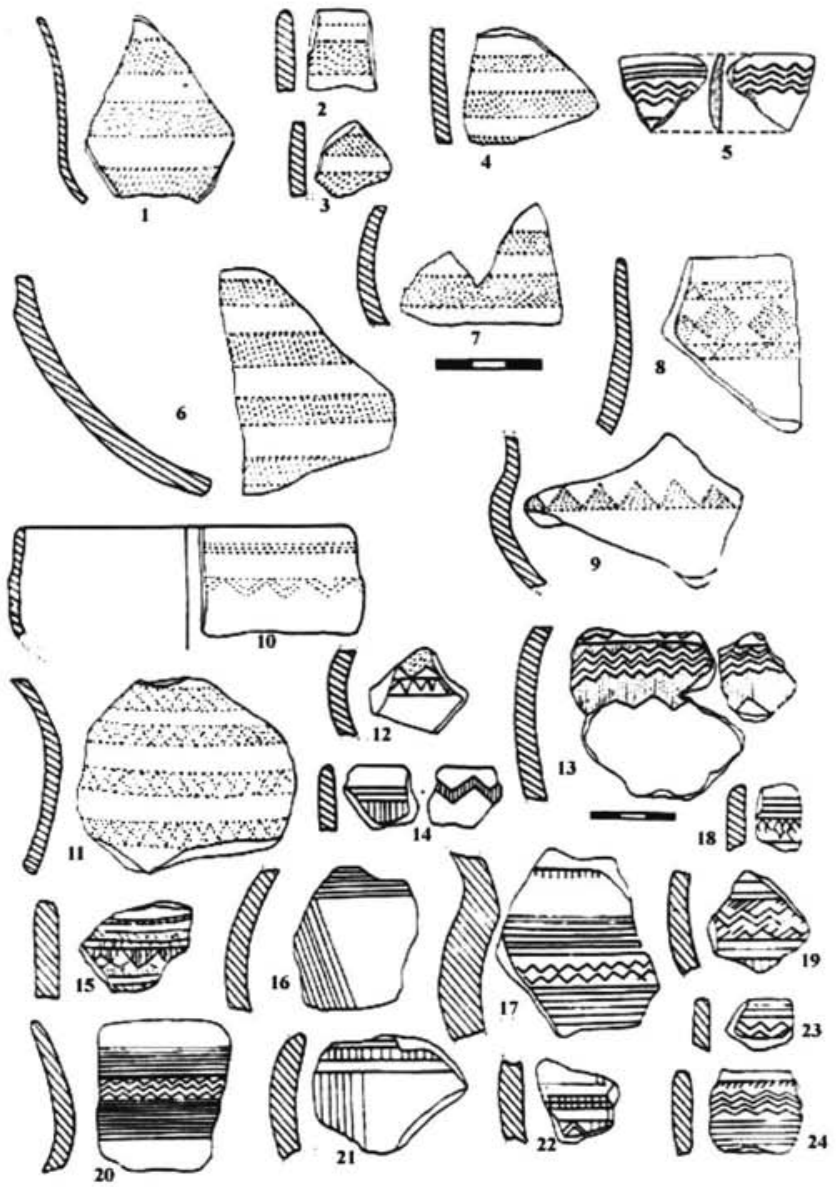

Figura 8 

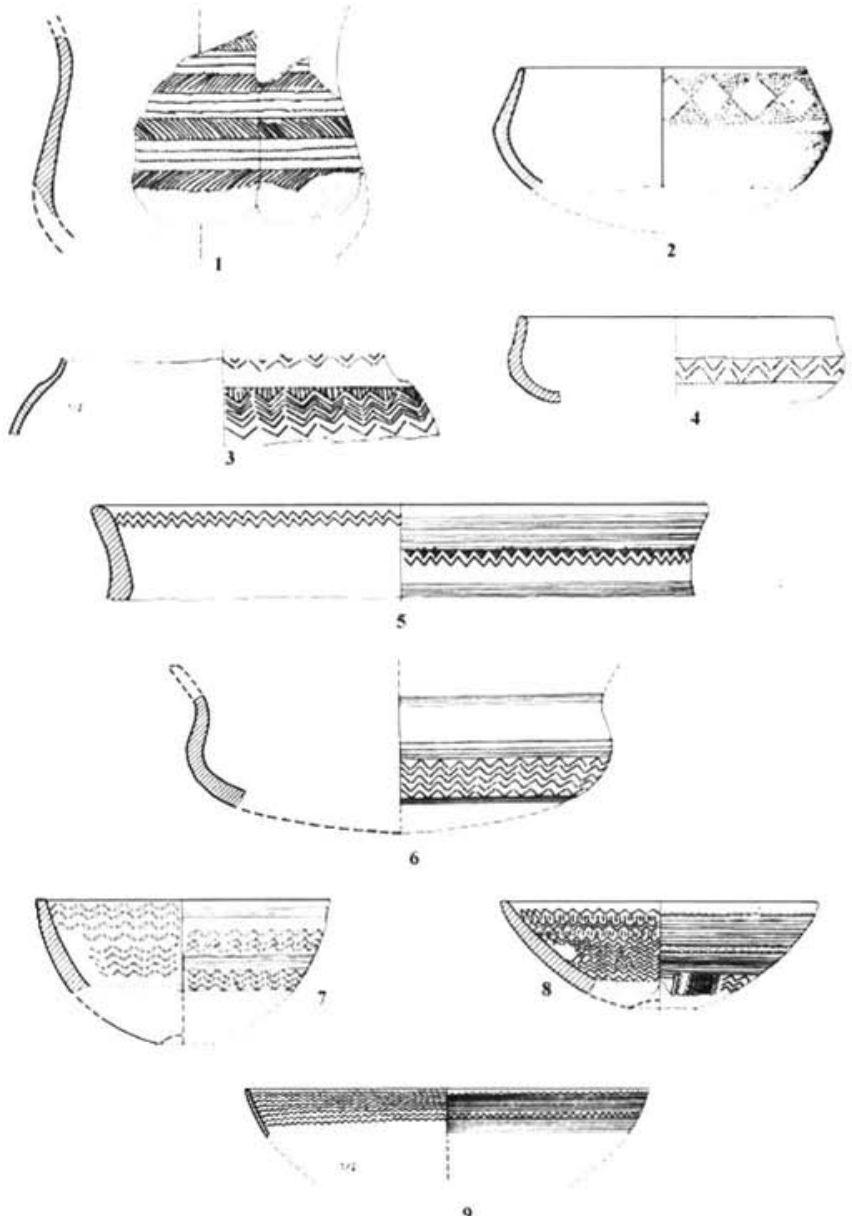

Figura 9 

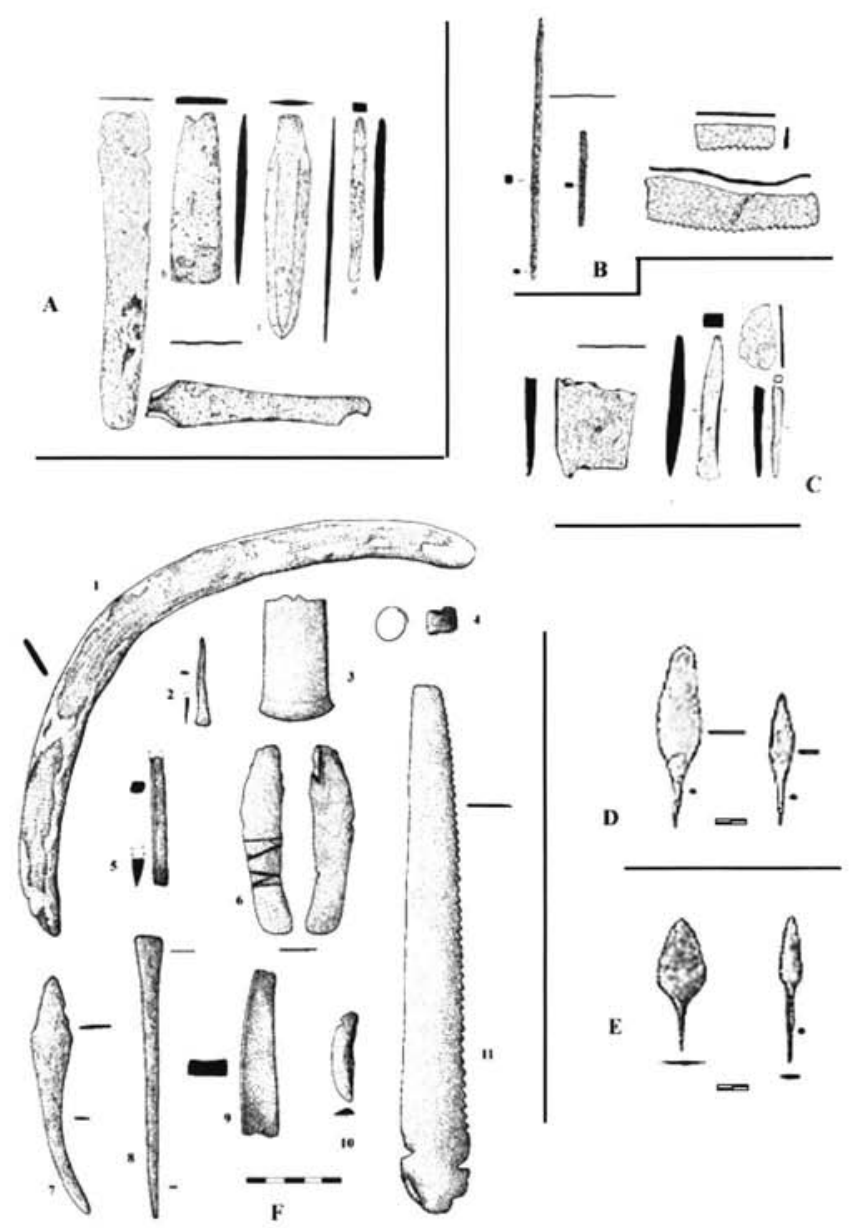

Figura 10 


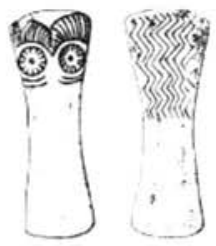

a

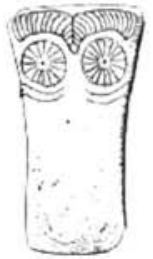

b
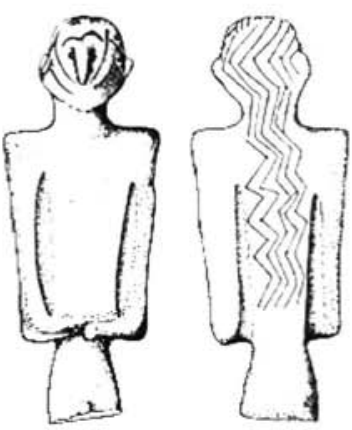

C

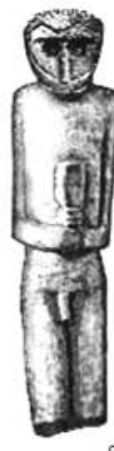

g
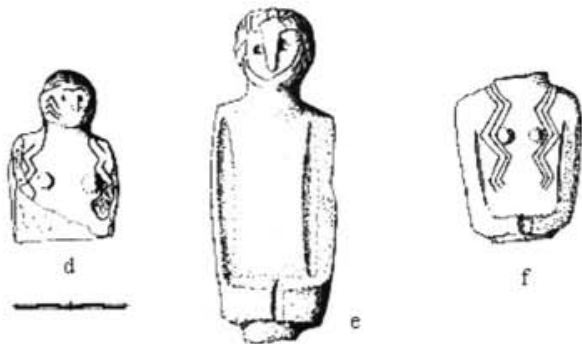

f

Idolos de La Pijotilla (a,b,d,e,f), Rena (c) y Llerena (g)

Figura 11 